\title{
Diabetic Nephropathy: A Cardiovascular Risk Factor
}

\author{
Caroline Jane Magri ${ }^{1,3}$ and Stephen Fava ${ }^{2,3}$ \\ ${ }^{1}$ Department of Cardiac Services, Mater Dei Hospital, Tal- Qroqq, Msida \\ 2Diabetes $\mathcal{E}$ Endocrine Centre, Department of Medicine \\ Mater Dei Hospital, Tal- Qroqq, Msida \\ ${ }^{3}$ University of Malta Medical School \\ University of Malta, Tal- Qroqq, Msida \\ Malta
}

\section{Introduction}

Diabetic nephropathy (DN) is an important and often life-threatening microvascular complication of diabetes mellitus (DM). It is usually first manifested as an increase in urinary albumin excretion (microalbuminuria), which progresses to overt albuminuria and then to renal failure (Mogensen et al., 1983). However, the EDIC/DCCT study showed that a significant number of patients develop renal insufficiency without the presence of microalbuminuria (Molitch et al., 2006).

The incidence of end-stage renal disease (ESRD) and type $2 \mathrm{DM}$ as a co-morbid condition has increased continuously during the past decades (Ritz \& Stefanski., 1996; Ritz \& Orth., 1999a) and has been named a medical catastrophe of worldwide dimensions (Ritz et al., $1999 \mathrm{~b})$. Thus, the proportion of diabetic patients among patients with treated ESRD ranges between 12 and 95\%, depending on nations and ethnicities investigated, with the majority (43-95\%) usually being type 2 diabetic subjects (Ismail \& Cornell, 1999).

A similar increase in the incidence of ESRD secondary to DM has been demonstrated following analyses of the United States Renal Data System data (USRDS 2004 Annual Data Report). Between 1999 and 2003, diabetes was responsible for $>44.8 \%$ of all new cases of ESRD in the United States. This increase could not be fully explained by changes in assignment of causes of ESRD, rising prevalence of DM, increased access to renal replacement therapy (RRT), increased acceptance of individuals with DM to ESRD programs, or increased survival of patients with DM (Jones et al., 2005). It has been suggested that external factors might be responsible for this growth in DN incidence.

Although diabetes has long been identified as a cardiovascular disease (CVD) risk equivalent, only recently has chronic kidney disease (CKD) been more widely recognized as an independent risk factor for CVD and all-cause mortality (Kidney Disease Outcomes Quality Initiative, 2004; Levey et al., 2003; Weiner et al., 2004; Go et al., 2004). In a study of more than 1 million ambulatory adult patients, the risk of a cardiovascular event and death due to any cause increased at every level of CKD below a GFR of $60 \mathrm{~mL} / \mathrm{min}$ per $1.73 \mathrm{~m}^{2}$, with a nearly 3.5-fold increased risk of a cardiovascular event and a 6-fold increased risk of 
death for those with a GFR of less than $15 \mathrm{~mL} / \mathrm{min} / 1.73 \mathrm{~m} 2$ (i.e. CKD stage 5) (Go et al., 2004). This has also been confirmed in diabetic subjects (Nag et al., 2007). In addition, microalbuminuria has been associated with an increased risk of CVD, both in patients with and without DM (Klausen et al., 2004; Gerstein et al., 2001; Dinneen \& Gerstein, 1997). Therefore, in patients with DN, the increased cardiovascular risk associated with diabetes and with CKD are additive and increase as DN progresses (Adler et al., 2003; Miettinen et al., 1996). Thus, in a retrospective claims-based study of more than 1 million Medicare enrollees aged 65 years and older, the risk of cardiovascular events was significantly increased in those with either CKD or diabetes alone, but cardiovascular risk was greatest when both conditions were present (Foley et al., 2005). Interestingly, many patients with CKD, particularly elderly patients, may be several times more likely to die of CVD before progression to ESRD (Collins et al., 2003). In view of all this, one realizes that early preventive measures and effective therapy are crucial. For this to achieved, the mechanisms underlying cardiovascular organ damage in patients with DN have to be better understood. A better understanding may further help to identify biomarkers for early detection of patients at high risk.

\section{Methods}

A comprehensive systematic review focusing on diabetic nephropathy as a cardiovascular risk factor was performed. Pubmed and Embase were used as electronic search engines. The search included all published papers and was not limited to human studies or to papers published in English. Cross-sectional, case-control and cohort studies, systematic reviews and meta-analyses were analysed to assess types of cardiovascular events observed in patients with DN, potential pathogenetic mechanisms, cardiac consequences of disturbed renal function, links between $\mathrm{DN}$ and CVD, possible biomarkers, as well as therapeutic strategies to deal with DN and CVD, as discussed below.

\section{Cardiovascular disease in subjects with diabetic nephropathy}

The evaluation of DN, from research and clinical viewpoints, depends on the assessment of two continuous variables, albumin excretion rate (AER) and glomerular filtration rate (GFR). Both have been associated with the increased CVD noted in DN, as discussed below.

\subsection{Cardiovascular disease in diabetic patients with macroalbuminuria}

The role of macroalbuminuria in CVD has been outlined in the post-hoc analyses of the Irbesartan Diabetic Nephropathy Trial (IDNT) and the Reduction of End points in NIDDM with the Angiotensin II Antagonist Losartan (RENAAL) studies. The IDNT enrolled subjects with type 2 DM, hypertension, and macroalbuminuria (Lewis et al., 2001). Irbesartan proved to be superior to amlodipine or placebo with respect to renoprotection but no difference was detected between treatment groups on the secondary outcome of cardiovascular (CV) events. A post hoc analysis was performed by Anavekar et al. (2004) to assess the relationship between baseline AER and the CV composite (CV death, nonfatal myocardial infarction (MI), hospitalization for heart failure, stroke, amputation, and coronary and peripheral revascularization). Univariate analysis revealed that $\mathrm{CV}$ events progressively increased with increasing quartiles of baseline AER while multivariate analysis confirmed albuminuria as an independent risk factor for cardiovascular events with a 1.3-fold 
increased relative risk for each natural $\log$ increase of $1 \mathrm{U}$ in urine albumin-creatinine ratio (ACR).

Similar results were noted in the Reduction of End points in NIDDM with the Angiotensin II Antagonist Losartan (RENAAL) whereby losartan was superior to placebo with regards to renoprotection in type 2 diabetic, hypertensive patients with macroalbuminuria. However it conferred no statistically significant benefit on the secondary CV outcomes (Brenner et al., 2001), although de novo heart failure was less frequently noted in the losartan group. Nevertheless, in a post-hoc analysis of RENAAL, baseline albuminuria was again shown to be a predictor of both the prespecified composite CV end point (composite of MI, stroke, first hospitalization for heart failure or unstable angina, coronary or peripheral revascularization, or CV death) as well as of heart failure alone. With subjects stratified into 3 groups on the basis of baseline ACR, comparison of the highest tertile with the lowest revealed an adjusted hazard ratio of 1.92 for the composite $C V$ end point and 2.70 for heart failure. In multivariate analysis, baseline albuminuria was the strongest independent predictor of both outcomes. In addition, the change in AER from baseline to 6 months was the only dynamic correlate of adverse CV outcomes. A 50\% reduction in baseline albuminuria translated into an $18 \%$ reduction in the composite $\mathrm{CV}$ end point and a $27 \%$ reduction in the risk of heart failure. It has thus been suggested that albuminuria serve as an indicator of therapeutic response.

\subsection{Cardiovascular disease in diabetic patients with microalbuminuria}

Microalbuminuria also correlates with adverse CV events. In a type 2 diabetic population, Mattock et al. (1998) reported that microalbuminuria was the strongest predictor of adverse CV outcomes with an odds ratio of 10.02. In addition, in the HOPE study, a baseline ACR $>2.0 \mathrm{mg} / \mathrm{mmol}$ (present in $32.6 \%$ of the diabetic cohort and $14.8 \%$ of the non-diabetic cohort) increased the adjusted relative risk of CV events (1.83), all-cause death (2.09), and hospitalization for congestive heart failure (3.23). In addition, the impact of microalbuminuria on the primary composite outcome of $\mathrm{CV}$ death, MI, or stroke was significant in both diabetic (relative risk 1.97) and non-diabetic (relative risk 1.61) subjects (Mann et al., 2004).

\subsection{Cardiovascular disease in diabetic patients with renal impairment}

Declining renal function plays an important role in CVD in diabetic patients, as demonstrated in the Valsartan in Acute Myocardial Infarction (VALIANT) trial. This was a multicentre, double-blind randomized controlled trial that enrolled patients with acute myocardial infarction (MI) complicated by either clinical or radiologic signs of heart failure and/or left ventricular dysfunction. Patients were randomly assigned to receive captopril, valsartan, or both. GFR was estimated using the 4-component MDRD equation. It was shown that the likelihood of experiencing the primary end-point of all-cause mortality was higher in patients with than without DM for each level of renal function. In addition, a decrease in eGFR of 10 units was associated with hazards of 1.09 (95\% confidence interval 1.06 to $1.12, \mathrm{p}<0.001)$ in patients with DM and 1.08 (95\% confidence interval 1.06 to 1.10 , $\mathrm{p}$ $<0.001$ ) in patients without DM for risk of fatal and nonfatal CV outcomes independent of treatment assignment (Anavekar et al., 2008).

The importance of renal impairment in predicting outcome following myocardial infarction in diabetic patients was also investigated by Ahmed et al. (2008). It was shown that the 
combination of renal impairment and DM was associated with a particularly high risk of MI and death/MI following a non-ST elevation MI, suggesting that attention to preserving renal function may be of particular benefit for reducing cardiovascular risk in diabetic patients.

\subsection{Diabetic nephropathy \& peripheral arterial occlusive disease}

Peripheral arterial occlusive disease (PAOD) is a major cause of morbidity, especially affecting the elderly population (1-3). In addition, the main cause of mortality in patients with PAOD is ischaemic heart disease (IHD) as has been shown in several studies, while subgroup analyses suggest that PAOD carries a particularly poor prognosis in diabetes (Davis et al., 2006; Li J et al., 2007).

$\mathrm{DN}$ has been reported to be associated with PAOD in both type 1 and type 2 diabetic subjects (Zander et al., 2002). Both albuminuria and declining GFR are probably associated with increased risk. Various studies have shown that PAOD is more prevalent in type 2 diabetic patients with increased albumin excretion rate (Mostaza et al., 2006; Bianchi et al., 2007). It is likely that microalbuminuria reflects widespread vascular damage. In addition, a reduction in GFR has been shown to be associated with PAOD in both non-diabetic ( $\mathrm{O}^{\prime}$ Hare et al., 2004) and diabetic patients (Mostaza et al., 2006; Bianchi et al., 2007). Albuminuria and declining renal function are also independent predictors of the occurrence of PAOD in nonCaucasian populations in both genders (Hsieh et al., 2009).

Interestingly, in a type 2 diabetic population with advanced microvascular disease, as evidenced by proliferative diabetic retinopathy requiring laser treatment, we have shown that increasing age, total cholesterol levels, and vibration perception thresholds, together with declining renal function and lower BMI are independent predictors of PAOD, whilst microalbuminuria was not (Magri et al., In press). This implies that the association between impaired renal function and PAOD is not solely mediated by microvascular disease. The lack of association of microalbuminuria with PAOD in our study is probably best explained by the fact that all our patients had advanced microvascular disease, as evidenced by proliferative diabetic retinopathy, and had been suffering from diabetes for a long duration (18.6 \pm 9.1 years). Therefore normoalbuminuric patients in our study probably represented a cohort which was genetically protected from diabetic renal disease. This suggests that the association of PAOD and microalbuminuria observed in other studies is mediated through shared environmental predisposing factors (example poor blood pressure and glycaemic control) in individuals who are genetically susceptible to develop renal disease.

Yoshimura et al. (2008) have shown that in type 2 diabetic patients with normal anklebrachial indices (ABIs), eGFR correlated positively with flow volume $(p=0.002)$ and negatively with brachial-ankle pulse wave velocity $(\mathrm{p}=0.0258)$ and with resistive index $(p=0.0029)$ in patients with albuminuria but not in those with normoalbuminuria. This implies an association between nephropathy and impaired lower limb circulation secondary to higher arterial stiffness and increased vascular resistance in type $2 \mathrm{DM}$. Similar results were shown in Japanese type 2 diabetic patients with normal ABIs where the major risk factors for reduced flow volume were age, hypertension, and DN $\left(\mathrm{r}^{2}=0.303, \mathrm{p}<0.001\right)$ (Suzuki et al., 2003). These results indicate that DN plays an important role in the early stages of PAOD in diabetes by altering vascular resistance and arterial stiffness.

A high ABI $(>1.40)$ has been found to be associated with an increased risk of CKD (defined as eGFR $<60 \mathrm{ml} / \mathrm{min} / 1.73 \mathrm{~m}^{2}$ ) in diabetic individuals at high cardiovascular risk (OR 2.4; 1.0-6.4) but not in non-diabetic patients (Liu et al., 2010). A high ABI is a marker of 
generalised stiffening of the lower limb arteries and is probably mediated through medial arterial calcification (MAC) in the majority of cases. MAC has been associated with increased left ventricular mass and aortic pulse-wave velocity in ESRD, leading to cardiac fibrosis and increased arrhythmia risk. Similar associations might be present in DM patients with high ABI but without severe renal disease, thus leading to increased cardiovascular morbidity and mortality. Nonetheless, Liu et al. conclude that further studies are needed to clarify the link between high ABI, CKD and CVD in diabetes.

\subsection{Diabetic nephropathy \& cerebral infarction}

CKD is a known risk factor for cerebrovascular disease. In addition, stroke is more common in type 2 diabetic subjects with nephropathy compared to type 2 diabetic subjects without nephropathy (Alwakeel et al., 2009; Alebiosu et al., 2004). The independent effects of albuminuria and eGFR on stroke and silent cerebral infarction in type 2 DM have been investigated by Bouchi et al. (2009 \& 2010, respectively). While a lower eGFR was associated with an increased risk of stroke in univariate analysis, it lost its significance in multivariate analysis. Clinical albuminuria remained a significant risk factor for stroke, with an adjusted HR of 2.40 (1.46-3.95, $\mathrm{P}=0.001$ ) compared with normoalbuminuria (Bouchi et al., 2009). Miettinen et al. (1996) have previously shown an association between proteinuria and incident stroke in type 2 diabetic patients. Similarly, in Japanese type 2 diabetic patients, both a high urinary albumin creatinine ratio and a low eGFR were significantly associated with silent cerebral infarction (SCI) (lacunar infracts) in univariate analysis; however only albuminuria remained a significant risk factor for SCI in multivariate analysis (Bouchi et al., 2010). SCI predicts incident clinically evident stroke, cardiovascular disease and dementia. Bouchi et al. (2010) conclude that the association between albuminuria and cerebrovascular disease could be explained either by common aetiological factors, including oxidative stress, inflammation, endothelial dysfunction, obesity, thrombotic state, hypertension and dyslipidaemia, or by similarities between the haemodynamic and anatomical aspects of renal and cerebral small vessel disease.

In type $1 \mathrm{DM}$ subjects, it has been shown that parents of patients with diabetic nephropathy have reduced survival which seems to be largely explained by an increase in vascular deaths, in particular, a four-fold increase in the number of strokes (Lindsay et al., 1999). Likewise, Thorn et al. (2007) have shown that type 1 diabetic patients with diabetic nephropathy had a higher prevalence of maternal (41 vs. $35 \%, p=0.046)$ and paternal (62 vs. $55 \%, \mathrm{p}=0.044)$ hypertension, maternal stroke $(7.6 \mathrm{vs} .5 .1 \%, \mathrm{P}=0.044)$, and paternal (4.3 vs. $2.9 \%, \mathrm{p}=0.030$ ) type 1 diabetes, compared to type 1 diabetic subjects without nephropathy. Similarly, parental hypertension has been associated with nephropathy in type 2 diabetic Pima Indians (Nelson et al., 1996).These data suggest that there is a shared hereditary risk factor predisposing diabetic patients to nephropathy and their parents to an increased risk of vascular disease, in particular stroke. This is likely to be largely mediated through a genetic predisposition to higher blood pressure, but other factors may also be involved.

\section{Cardiovascular consequences of diabetic nephropathy}

Disturbed renal function in DN leads to a multitude of adverse cardiovascular effects, as outlined in Figure 1. Increased blood pressure together with accelerated large vessel disease and increased arterial stiffening and calcification lead to increased afterload whilst hypervolaemia and anaemia lead to increased preload with consequent adverse effects on 
the heart. These cardiac abnormalities are further augmented by the local activation of the renin-angiotensin system (RAS) and endothelin (ET) system, amongst others. The RAS plays a role in the activation of the sympathetic nervous system, the dysregulation of endothelial function and progression of atherosclerosis, and inhibition of the fibrinolytic system, while direct profibrotic actions of angiotensin II and aldosterone in the kidney and heart promote end-organ injury. On the other hand, serum ET-1 levels were found to be associated with left ventricular hypertrophy.

Increased blood pressure is an early feature of renal disease and undoubtedly contributes to the excess cardiovascular risk (reviewed by Ritz et al., 2010). High blood pressure also predisposes to renal disease and predates the onset of diabetic nephropathy (Nelson et al., 1993). Therefore patients with high blood pressure are at risk of developing both renal and cardiovascular disease. However high blood pressure is also a consequence of renal disease, thereby initiating a vicious cycle resulting in progression of CKD as well as in CKD being causally related to increased cardiovascular risk. An extensive discussion of the mechanisms of these inter-relationships between blood pressure and kidney disease is beyond the scope of this review.

Left ventricular hypertrophy $(\mathrm{LVH})$ is an important risk factor for adverse cardiovascular outcomes in patients with CKD. LVH has been demonstrated to be an important predictor of cardiovascular mortality in type 2 diabetic subjects with and without DN (Astrup et al., 2007). In addition, there is increasing LVH with progression of nephropathy (Alebiosu et al., 2008; Suzuki K et al., 2001). A potential pathogenic role of parathyroid hormone on LVH has been suggested, together with its effect on interstitial fibrosis and thickening of intramyocardial arterioles (Amann et al., 1994). This is consistent with several clinical findings showing a positive correlation between parathyroid hormone concentration and cardiovascular morbidity and mortality in dialysis patients (Block et al., 1998). Interestingly, cardiovascular autonomic neuropathy (CAN) as indicated by impaired parasympathetic nervous system function, has been shown to be associated with the presence of LVH in diabetic patients on haemodialysis. This suggests that the co-existence of CAN and LVH may be one of the key factors for the high incidence of cardiovascular events in diabetic haemodialysis patients (Nishimura et al., 2004). Likewise, Weinrauch et al. (2006) have demonstrated regression of LVH in DN patients occurring in parallel with improvement in cardiac autonomic function, as determined from heart rate variability. The authors conclude that there is a common mechanism linking LV mass and CAN, such that improvement in LV mass might be predicted through analysis of baseline heart rate variation.

In a study in patients with CKD stages 2-4, approximately half of whom were diabetic, McQuarrie et al. (2010) have shown that the degree of albuminuria is independently and significantly associated with left ventricular mass, as assessed using volume-independent cardiac magnetic resonance imaging; this relationship was shown to be independent of blood pressure. These findings suggest that the increased left ventricular mass provides a potential link between elevated protein excretion, left ventricular hypertrophy (LVH) and the increased mortality seen in patients with CKD.

Left ventricular diastolic dysfunction is another adverse cardiac effect (Figure 2). In a study of 67 patients with non-dialysis CKD, Miyazoto et al. (2005) found that DN is a significant predictor of LV diastolic dysfunction in CKD subjects, independent of other influencing factors such as age, blood pressure, renal function, anaemia and LV hypertrophy. LV diastolic dysfunction is characterized by elevated left ventricular end-diastolic pressure or 
left arterial pressure, ultimately leading to LV systolic dysfunction and overt heart failure symptoms.

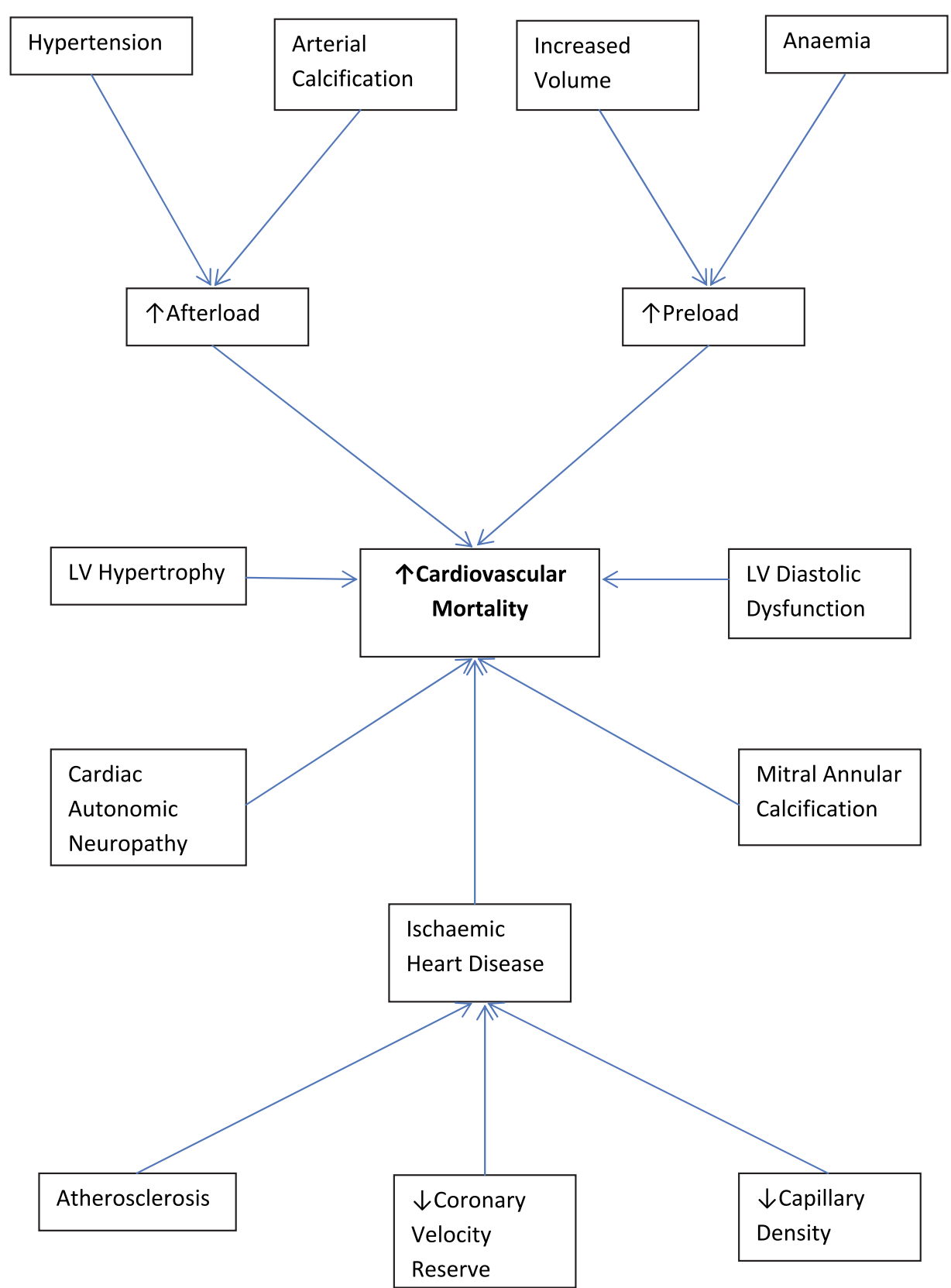

Fig. 1. Cardiovascular Consequences of Diabetic Nephropathy 


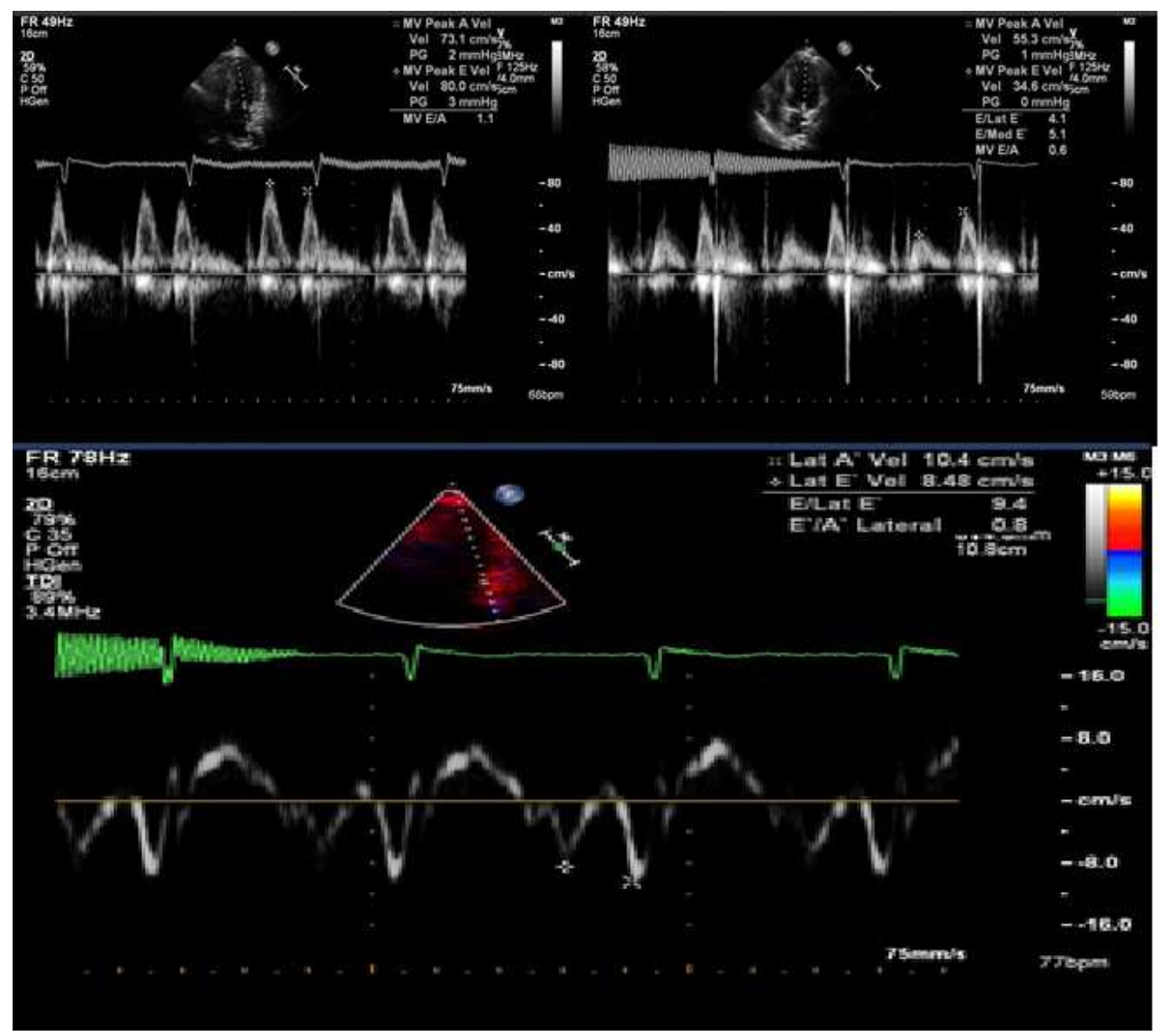

Fig. 2. Doppler evidence of left ventricular diastolic dysfunction. (A) Mitral inflow pattern during normal breathing (B) Mitral inflow pattern during Valsalva manoeuvre showing reversibility of inflow pattern $(\mathrm{E}<\mathrm{A})$, typical of restrictive pattern of diastolic dysfunction (C) Tissue Doppler evidence indicating diastolic dysfunction

Mitral annular calcification (MiAC) is another important cardiac abnormality found in patients with CKD. This is because MiAC has been shown to predict atrial fibrillation, stroke and cardiovascular disease morbidity and mortality. In the Framingham Heart Study (Fox et al., 2006), 3047 participants (some of whom had CKD secondary to diabetes) were assessed for the presence of mitral annular calcification (MiAC), aortic sclerosis and aortic annular calcification. It was demonstrated that the combination of both CKD and MiAC was associated with a three-fold increased risk of death compared with those with neither CKD nor MiAC $(p=0.0004)$, following adjustment for age and gender. Interestingly, the association between CKD and MiAC occurred before the onset of ESRD; however, no significant association was found between CKD and either aortic sclerosis or aortic annular calcification (odds ratio 1.1 and 1.1, respectively). It is still unclear whether MiAC is a causal mechanism that mediates this association or a risk marker; further research is needed to unveil underlying pathophysiologic mechanisms. 
Ischaemic heart disease (IHD) is strongly associated with DN. Patients with both ESRD and diabetes mellitus carry an increased risk of coronary atherosclerosis. The possible mechanisms are discussed in section 5. In addition to coronary atherosclerosis, abnormalities in myocardial blood flow and in coronary flow reserve could be responsible for cardiovascular morbidity in DN. Ragosta et al. (2004) have demonstrated that subjects with $\mathrm{DN}$ and normal coronary arteries had abnormalities in coronary velocity reserve (CVR). Abnormal CVR was caused by an elevation of baseline arterial peak velocity in $66 \%$ of these cases. The elevated baseline velocity may be caused by an increase in LV mass from associated long-standing hypertension, or by circulating humoral factors with vasodilator properties present in renal failure, for example nitric oxide. In addition, the baseline heart rate and the presence of diabetes mellitus with renal failure were independent predictors of abnormal CVR by multivariable analysis. Therefore, in the presence of end-organ damage caused by diabetes mellitus, abnormalities in coronary physiology may be seen in the absence of overt epicardial coronary artery disease.

In addition to arterial changes, reduction in capillary density is another important factor in CKD which interferes with oxygen delivery. In uraemic subjects with LVH, there is a significant decrease in capillary density, leading to an increase in intercapillary distance, and potentially compromising the blood and oxygen supply of the myocardium under conditions of increased demand, thus rendering the myocardium more prone to ischaemic injury. $\mathrm{LVH}$ is common in diabetic subjects secondary to concomitant hypertension. These findings suggest that in uraemic patients with $\mathrm{LVH}$, there is probably decreased expression of vascular endothelial growth factor or increased expression of inhibitors of capillary angiogenesis, such that capillary growth does not keep pace with cardiomyocyte growth (reviewed by Amann et al., 2006). It is possible that low capillary density or poor capillary recruitment puts subjects at risk of developing hypertension, kidney disease as well as cardiovascular disease. Further studies are needed to clarify the pathological mechanisms underlying the decrease in cardiac capillary supply.

\section{Potential pathogenic mechanisms}

Various mechanisms account for the cardiovascular dysfunction present in renal disease, as outlined below.

\subsection{Endothelial cell dysfunction}

The vascular endothelium is a versatile multifunctional tissue having many synthetic and metabolic properties (Figure 3). Endothelial cell dysfunction seems to be central in the genesis of many different aspects of cardiovascular dysfunction in subjects with DN, such as increased pulse wave velocity (Yokoyama et al., 2004) and decreased flow-mediated dilation (FMD) of the brachial artery (Yilmaz et al., 2008). Table 1 outlines the various factors leading to endothelial cell dysfunction.

Yilmaz et al. (2008) have demonstrated that endothelium-dependent vascular dysfunction, as assessed using FMD, correlates with proteinuria in type 2 diabetic subjects with early DN. Interestingly, no correlation was found between proteinuria and nitroglycerine-mediated dilation (NMD) of the brachial artery. This suggests that there decreased bioavailability of nitric oxide (NO), but that the vessels remain responsive to it in DN. In addition, a positive association was found between proteinuria and the intracellular protein nicotinamidephosphoribosyltransferase (NAMPT)/visfatin, which is thought to be a marker of endothelial 
cell damage. On the other hand, there were negative associations between proteinuria and two vasoprotective molecules, namely adiponectin and fetuin-A. The authors suggest that proteinuria might lead to endothelial dysfunction via increasing serum levels of the NOsynthase inhibitor ADMA, probably secondary to increased protein turnover, together with loss of vasoprotective circulating proteins such as adiponectin and fetuin.

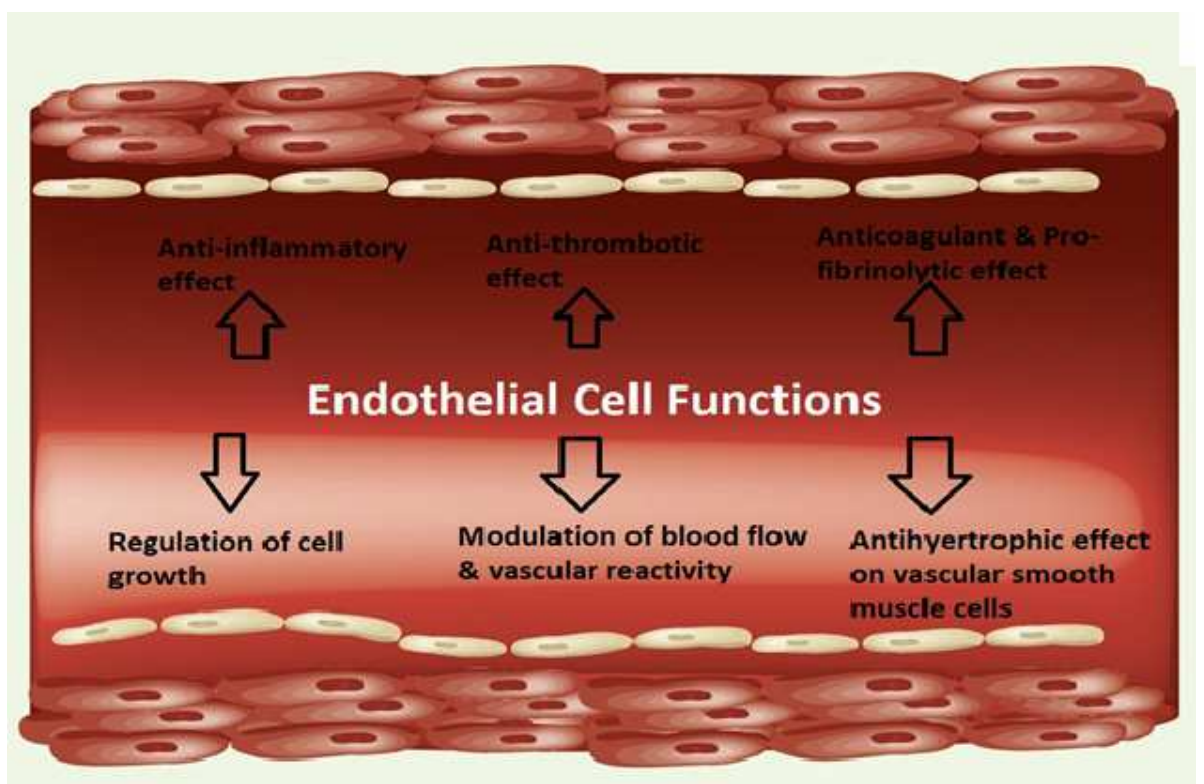

Fig. 3. Endothelial Cell Properties \& Functions (Reproduced from Expert Review of Cardiovascular Therapy, October 2011, Vol. 9, No. 10, Page 1280 with permission of Expert Reviews Ltd)

\begin{tabular}{|ll|}
\hline - & $\uparrow$ Asymmetrical dimethylarginine \\
- & $\downarrow$ Adiponectinlevels \\
- & $\downarrow$ Fetuinlevels \\
- & Rsulin resistance \\
- & Runin-angiotensin system activation \\
- & Thomocysteinelevels \\
\hline
\end{tabular}

Table 1. Factors leading to endothelial cell dysfunction 
Asymmetrical dimethylarginine (ADMA) is an endogenous competitive nitric oxide (NO) synthase inhibitor. It can be metabolized by dimethylarginine dimethylaminohydrolase (DDAH) or excreted by the kidneys (Leiper et al., 2006). It is increased in patients with increased cardiovascular risk (Kielstein et al., 1999; Zoccali et al., 2002; Surdacki et al., 1999) and predicts future cardiovascular events (Schnabel et al., 1995). Accumulation of ADMA in CKD could promote atherosclerosis and is related to a history of myocardial infarction and/or stroke in patients with type 1 DM and macroalbuminuria (Tarnow et al., 2004). In type 2 diabetic patients with albuminuria, increased ADMA was also shown to be linked to macrovascular disease, and is associated with declining GFR and subclinical inflammation, as assessed using high senstivity C-reactive proten (hsCRP) (Krzyzanowska et al., 2007).

In addition to its direct inhibitory effect on endothelial NO synthase, ADMA may cause endothelial dysfunction via other mechanisms. These include increased superoxide production by activation of the $\mathrm{NAD}(\mathrm{P}) \mathrm{H}$-oxidase, thereby interfering with $\mathrm{NO}$ bioavailability; activation the local RAS, thus contributing to the development of arteriolar dysfunction and increased tone; and a decrease in the number of circulating endothelial progenitor cells (EPCs), possibly interfering with vascular repair mechanisms (reviewed by Fliser, 2010).

Insulin resistance also plays an important role in endothelial dysfunction. Insulin resistance has been associated with renal disease in both types 1 (Yip J et al., 1993) and 2 (Groop et al., 1993) diabetes, thereby offering another possible explanation of the association between cardiovascular disease and DN. Furthermore, endothelial cell injury has recently been linked to increased shear stress (Boulanger et al., 2007). The latter is known to be associated with high blood pressure.

Plasma levels of the soluble receptor for advanced glycation end-products (RAGE) are strongly associated with CVD in patients with DN (Nin et al., 2010). RAGE has been shown to induce the production of adhesion molecules and inflammatory cytokines, thus promoting endothelial and renal dysfunction, low grade inflammation and vascular remodeling. Through these mechanisms, RAGE may contribute to both DN and cardiovascular disease.

Activation of the renin-angiotensin system in DN results in endothelial dysfunction. When angiotensin II acts through the AT1 receptor, it stimulates the generation of reactive oxygen species by $\mathrm{NAD}(\mathrm{P}) \mathrm{H}$ oxidase and other enzyme systems, leading to upregulation of inflammatory mediators, which include cytokines, chemokines, adhesion molecules, and plasminogen activator inhibitor 1 , and superoxide scavenging of NO. These events promote endothelial dysfunction, vascular remodeling, and the progression of atherosclerosis (Schiffrin et al., 2004).

There is also evidence that hyperuricaemia induces endothelial dysfunction by inhibiting NO production (Khosla et al., 2005), modulates inflammatory response (Kang et al., 2005), and stimulates vascular smooth muscle cell proliferation. In a study by Correa Leite (2011), a decline in GFR was associated with an increase in CVD risk factors (increased fibrinogen and hematocrit levels) only among subjects with higher uric acid levels. These alterations may promote thrombotic disorders via a hypercoagulable state and increase in blood viscosity. Consequently, serum uric acid measurement in patients with mild renal impairment may serve as a potentially useful means of identifying subjects at risk of developing CVD.

Hyperhomocysteinaemia may also play a role in endothelial dysfunction. Elevated plasma homocysteine levels are associated with albuminuria in both type 1 (Soedamah-Muthu et al., 
2005) and type 2 diabetic patients (Aso et al., 2004). It has been suggested that elevated total homocysteine levels cause vascular complications secondary to oxidative stress, endothelial damage and decreased nitric oxide bioavailability. In addition, the increased susceptibility of diabetic subjects to hyperhomocysteinaemia may be secondary to an acceleration of glucose-induced oxidative stress on endothelial cells (Soedamah-Muthu et al., 2005). This hypothesis is supported by animal studies showing that homocysteine-induced endothelial dysfunction occurs much more readily in the presence of diabetes than in its absence (Schukla et al., 2002).

\subsection{Endothelial progenitor cells}

Bone marrow-derived EPCs in peripheral circulation contribute to re-endothelialization of injured vessels as well as to neovascularization of ischaemic lesions and therefore play a key role in maintaining the integrity of the vascular system. Various factors influence the number and function of EPCs. Mild-to-moderate renal dysfunction accompanying stable angina has been shown to be associated with EPC depletion, irrespective of angiographic CAD extent. This may exacerbate an imbalance between endothelial injury and EPC-mediated repair, thus contributing to high cardiovascular risk in CAD coexisting with renal insufficiency. In addition, the number of EPCs is decreased in both patients with type 1 and type 2 DM, and EPCs from patients with DM have impaired function of adhesion, proliferation, and tubulization. All these findings indicate that EPCs play an important role in the pathogenesis of DN.

Interestingly, erythropoietin (EPO) has been shown to be a potent stimulator of EPC proliferation and differentiation. In addition, EPO has important direct biological effects on mature endothelial cells, including protection against ischemia and apoptosis, modulation of endothelial cell-cell and cell-matrix contacts, enhancement of endothelial cell migration and formation of primitive vascular structures in vitro. Mature endothelial cells do not lose their EPO receptors, unlike erythrocytes; hence, antiapoptotic signaling persists much longer, making endothelial cells more resistant to ischemia-induced cell death. Fliser (2010) thus suggests that EPO might be a key regulator of vascular protection. The adverse effects noted with use of recombinant human EPO (rHuEPO) could be attributed to the abrupt increase in the hematocrit level in CKD patients with serious vascular problems. In addition, rHuEPO increases the number and activation of thrombocytes, while increasing platelet adherence to the injured endothelium. However, the increase in hematocrit related to rHuEPO treatment is not associated with an increased risk for thrombosis as long as endothelial NO production serves as the compensatory mechanism. Consequently, there is ongoing research for an optimal rHuEPO dose that is safe, or EPO analogues (example the carbamylated form of EPO) that maintain tissue protective effects but lack the adverse effect on erythropoiesis and thrombopoiesis (Fliser, 2010).

\subsection{Inflammation}

CKD results in a chronic, low-grade inflammatory process that becomes evident even in the early stages of the disease. Circulating levels of inflammatory markers, such as C-reactive protein (CRP) and interleukin-6 (IL-6), are elevated in CKD patients. Navarro et al. (2008) have recently shown a relationship between inflammatory activation of peripheral blood mononuclear cells (reflected by enhanced mRNA expression of TNF-alpha and IL-6) and renal involvement (reflected by increased urinary albumin excretion) in type 2 diabetic 
patients. Increased inflammation could thus play a role in accelerated atherosclerosis and increased cardiovascular risk associated with DN.

\subsection{Advanced glycation end-products}

Advanced glycation end-products (AGEs) are products of non-enzymatic glycation and oxidation of proteins and lipids. They are increased in situations with hyperglycemia and oxidative stress such as DM. The kidney plays an important role in clearance and metabolism of AGEs. In CKD, AGE concentrations increase, partly by an increase in oxidative and carbonyl stress, leading to structural renal changes with further CKD progression, thus creating a vicious circle.

AGEs and their receptors play an important role in the pathophysiology of DN (reviewed by Busch et al., 2010). Besides vascular damage, RAGE drives the development of glomerulosclerosis and promotes podocyte activation in DN. Accumulation of AGEs affects almost all renal structures, including basement membranes, mesangial and endothelial cells, podocytes and tubules. In addition, medial smooth muscle cell injury in intrarenal arteries is caused by interaction between glycoxidation and complement activation, leading to progression of DN. AGEs and RAGE also are thought to play a key role in predisposing to cardiovascular disease in CKD patients (Noordzij et al., 2008; Lindsey et al., 2009).

However, even though AGEs and their receptors are involved in the pathogenesis of vascular and kidney disease, the role of circulating AGEs as biomarkers for cardiovascular risk estimation is questionable. In a post-hoc analysis of type $2 \mathrm{DM}$ patients having DN from the IDNT cohort (Lewis et al., 2001; Berl et al., 2003), serum concentration of carboxymethyllysine (an important AGE) was not found to be an independent cardiovascular or renal risk factor (Busch et al., 2006). This may be due to the fact that serum concentrations failed to correlate with AGEs deposited in target tissues. Nonetheless, further research is needed to elucidate the role of AGEs and their receptors in the pathophysiology of DN and associated co-morbidities. In addition, there is ongoing research on the possible therapeutic benefit of inhibitors of AGE formation and putative breakers of already formed AGEs in the prevention and treatment of patients with DN and diabetic cardiovascular disease.

\subsection{Lipoprotein abnormalities}

Lipoprotein abnormalities also play a role. DN is characterized by low high-density lipoprotein (HDL)-concentrations and elevated intermediate-density lipoprotein (IDL), both of which contribute to an increased cardiovascular risk. Shoji et al. (2001) have demonstrated that elevated serum creatinine has greater impact than albuminuria on abnormalities in IDL and HDL. In addition, in diabetic patients, serum lipoprotein (a) concentration is associated with albuminuria, further contributing to the elevated cardiovascular risk (Hernández et al., 2000).

\subsection{Adhesion molecules}

Elevated plasma concentrations of soluble adhesion molecule concentrations in patients with DN could play an important role in the development of atherosclerosis and increased cardiovascular risk. Thus, plasma concentration of soluble intercellular adhesion molecule (sICAM)- 1 is elevated in type 1 diabetic patients with microalbuminuria and the concentrations of sICAM-1 as well as soluble vascular adhesion molecule (sVCAM)-1 are elevated in patients with macroalbuminuria and normal serum creatinine (Clausen et al., 2000). 


\subsection{Hyperfibrinogenaemia}

Hyperfibrinogenaemia is a cardiovascular risk factor. Tessari et al. (2006) have shown an upregulation of hepatic secretory proteins, albumin and fibrinogen, in albuminuric type 2 DM subjects compared with type 2 DM normoalbuminuric patients. Such an upregulation seems to be responsible for the hyperfibrinogenaemia observed in the albuminuric diabetic patients, and could thus play a role in the adverse cardiovascular effects noted in this high risk population.

\subsection{Cardiac autonomic neuropathy}

Cardiac autonomic neuropathy (CAN) is another important mechanism. In type 2 DM patients, CAN and DN were found to be independently associated with asymptomatic CAD (Beck et al., 1999). In type 1 DM patients with nephropathy, CAN assessed as heart-rate variation during deep breathing was shown to be an independent risk factor for cardiovascular morbidity and mortality (Astrup et al., 2006). In addition, autonomic neuropathy may be associated with increased central arterial stiffness (Nemes et al., 2010). The mechanisms by which CAN increases cardiovascular morbidity and mortality are still under debate. Suggested mechanisms include impaired central control of respiration in patients with CAN (Sobotka et al., 1986); exercise intolerance with a reduced response in heart rate and blood pressure and decreased cardiac output during exercise; and possibly QT prolongation (Whitsel et al., 2000; Veglio et al., 2000).

\section{Other possible links between cardiovascular disease \& diabetic nephropathy}

Several hypotheses have been proposed to explain the link between the kidney and cardiovascular disease. These have been reviewed by Amann et al. (2006) and are outlined below.

Local factors may play a role in the cross-talk between the kidney and the cardiovascular system. The original Steno hypothesis (Deckert et al., 1989) suggested that enzymes involved in the metabolism of anionic components of the extracellular matrix (e.g. heparan sulphate proteoglycan) vulnerable to hyperglycaemia are probably the primary cause of albuminuria and the associated complications. Genetic polymorphisms of these enzymes could explain the variation in susceptibility to diabetic nephropathy and cardiovascular disease. However, there is little evidence supporting this hypothesis. An alternative hypothesis is a common glycocalyx defect in the glomerulus and in the systemic circulation. This is because the endothelial glycocalyx plays a significant role in the genesis of vascular pathology and controls vascular permeability (Gouverneur et al., 2006; Henry \& Duling, 1999). This might also be the case in the glomerulus; however this merits further study.

Amann et al. also propose various pathways through which reduced renal function might influence endothelial function. These include the following:

1. Accumulation of toxins that are normally excreted via the kidneys

2. Inability of the kidney to produce active substances, example renalase. Renalase is an enzyme which breaks down catecholamines like adrenaline and noradrenaline in the circulation; its levels are markedly decreased in subjects with end-stage renal disease. In rodents, renalase has been shown to decrease blood pressure, heart rate, heart muscle contractility, and blood vessel resistance. 
3. Reduced metabolism of substances normally metabolized by the kidney, example ADMA. The plasma concentration of ADMA are moderately elevated in renal failure, resulting in modification of gene expression patterns in endothelial cells as well as diminished production of nitric oxide secondary to inhibition of NO synthase.

Systemic factors may also play a role. Atmann et al. mention enhanced sympathetic activity at an early stage of renal disease when whole-kidney GFR is still normal. It is thought to be due to increased afferent signals originating from the damaged kidney, possibly contributing to increased incidence of sudden death and mortality secondary to ischaemia in renal patients. However, the triggering intrarenal mechanisms have not yet been identified. In addition, Atmann et al. propose the possibility of inappropriate activation of local RAS of cardiovascular structures in subjects with kidney disease, as suggested by animal studies where local cardiovascular RAS activation was noted in uraemic or subtotally nephrectomised rats.

Genetic influences probably also play a role. It has recently been shown that the P12A and C161T polymorphisms of the PPAR-gamma gene are important predictors of cardiovascular events in patients with diabetic nephropathy. The Pro/Ala genotype of the P12A polymorphism confers a 7.6-fold (95\% CI 2.1- to 28.0-fold, $\mathrm{p}=0.002)$ excess hazard of developing primary cardiovascular end point as compared to the Pro/Pro genotype, while each $\mathrm{T}$ allele at the 161 position confers a $83.4 \%(95 \%$ CI $15.2-291.9 \%, \mathrm{p}=0.011)$ excess hazard (Szeto et al., 2008). Another interesting polymorphism is the leucine 7 to proline 7 (Leu7Pro) polymorphism, located in the signal peptide part of the human preproneuropeptide Y (Pettersson-Fernholm et al., 2004). In the Finnish Diabetic Nephropathy Study, the Pro7 substitution was more common in patients with proteinuria than in those with normoalbuminuria (16 vs. $11 \%, \mathrm{p}<0.05)$. Patients with the Pro7 allele had worse glycemic control $(\mathrm{HbA}(1 \mathrm{c}) 8.8$ vs. $8.5 \%$, p < 0.005), more coronary heart disease (CHD) (14 vs. $8 \%, \mathrm{p}<0.05)$, and higher serum triglycerides (1.65 vs. $1.35 \mathrm{mmol} / \mathrm{l}, \mathrm{p}<0.005)$ than patients with the wild-type genotype. In multivariate analysis, the Leu7Pro polymorphism was independently associated with $\operatorname{HbA}(1 \mathrm{c})(\mathrm{p}<0.001)$, proteinuria ( $\mathrm{p}<0.01)$, and CHD ( $\mathrm{p}<0.01)$, suggesting that the Leu7Pro polymorphism may contribute to the genetic susceptibility to diabetic nephropathy and CHD in type 1 diabetic patients, possibly by influencing glycemic control and triglycerides.

Recently, Takenaka et al. (2010) have shown that short stature is associated with increased mortality in diabetic and non-diabetic subjects with ESRD. Short stature has been linked to nephropathy in both type 1 (Rossing et al., 1995) and type 2 diabetes (Fava et al., 2001); height may therefore partly explain the association between DN and cardiovascular disease. This may be due to common genetic and/or environmental factors predisposing to short stature, DN and cardiovascular disease.

In addition to genetic influences, Brenner et al. (1988) have suggested the hypothesis of "nephron underdosing" whereby aberrant foetal programming secondary to genetic factors, malnutrition, and other insults in utero leads to the formation of fewer glomeruli. This results in a diminished ability to excrete sodium and thus predisposes to salt-sensitive hypertension. In favour of this hypothesis is the observation that both diabetic and nondiabetic renal diseases are seen more frequently in families with hypertension. In addition, in normoalbuminuric subjects, the risk for future ESRD is predicted by baseline blood pressure (Hsu et al., 2005). Congenital variability in filtration surface area may explain the varying susceptibility of patients exposed to potentially injurious renal stimuli to eventually manifest chronic nephropathy, as well as the different susceptibility of subsets of type 1 and type 2 diabetics to 
develop overt glomerulopathy. Ots et al. (2004) have shown that kidney transplantation in 5/6 nephrectomized animals protects against albuminuria and rise in blood pressure. In humans, single kidney GFR declines more rapidly in uninephric individuals compared to binephric ones (Saxena et al., 2006). Undoubtedly, the role of foetal programming on the occurrence of renal and cardiovascular disease needs further study.

\section{Therapeutic strategies}

A major limitation in the interventions needed to reduce cardiovascular risk in subjects with $\mathrm{DN}$ is the fact that in the past renal patients were deliberately excluded from major intervention studies. Hence, current recommendations are mainly based on observational studies or post-hoc analyses of patients with early stages of CKD who had been enrolled in randomized controlled trials. However, information from controlled trials is available for some interventions, as outlined below.

\subsection{Blood pressure control}

The most important component of treatment is blood pressure (BP) control. Numerous studies have shown that the use of antihypertensive treatment in patients with DN is crucial in the preservation of GFR (Mogensen, 1982; Anderson et al., 1988; Parving et al., 1993) and to reduce mortality in this high-risk group (Parving et al., 1989; Mathiesen et al., 1989). In view of the fact that diabetic patients are a high risk population, the Seventh Report of the Joint National Committee on Prevention, Detection Evaluation and Treatment of High Blood Pressure (JNC 7) (2003) and American Diabetes Association (2004) have recommended a BP target of 130/80 mm Hg in diabetic patients and <125/75 mm Hg (Compendium of ESC Guidelines 2007) in the presence of renal impairment or of significant proteinuria $>1 \mathrm{gr} / 24$ hours. Nonetheless, BP lowering should be gradual and monitored closely, especially in haemodialysis patients who often develop hypotensive episodes during fluid removal by ultrafiltration. This is especially important in this high-risk population, keeping in mind that low blood pressure predicts death, particularly in the elderly with high comorbidity and low diastolic blood pressure values.

RAS blockade is the cornerstone of treatment of $\mathrm{DN}$, as discussed below. In addition, diuretics play a crucial role in the treatment of CKD by potentiating the pressure lowering effect of RAS inhibitors. However, diuretics do have adverse effects on the heart and kidneys by triggering counterbalancing antinatriuretic mechanisms, example ACE II, aldosterone, decreased systemic blood pressure, and it is therefore advised that the lowest effective dose should be administered.

Importantly, the combination of RAS inhibitors and low dose thiazide diuretics augments the reduction of albuminuria. Also, RAS inhibitors diminish the thiazide-induced reduction in GFR. As a result, the filtered sodium load is increased, permitting more effective natriuresis. However, in patients with GFR $<30 \mathrm{~mL} / \mathrm{min}$, thiazides cause only a minor increase of natriuresis and they should therefore be exchanged for, or combined with, loop diuretics which are effective even in advanced CKD. In addition, in DN and proteinuric patients, higher diuretic doses are required because in the tubule lumen diuretics are up to $90 \%$ protein bound and natriuresis is only determined by the concentration of the free diuretic.

$\beta$-blockers, example carvedilol and nebivolol, are useful second-line treatments. Traditionally the use of $\beta$-blockers has been discouraged in patients with diabetes because 
they were associated with adverse effect such as weight gain, reduced peripheral blood flow, pronounced hypoglycemia and nightmares. However, $\beta$-blockers help decrease the enhanced sympathetic activity present in kidney disease. In addition, cardioselective $\beta$ blockers have less renal circulatory side effects and are associated with less blunting of hypoglycemia awareness and with less elevation of lipid and glucose levels, and are thus preferred to the nonselective type.

Dihydropyridine calcium antagonists should be avoided in hypertensive patients with albuminuria, as suggested by the results of a study conducted by Hummel et al. (2010). The latter have shown that dihydropyridine calcium antagonists are associated with increased albuminuria in patients treated with ACE inhibitors (ACEI)/ angiotensin receptor blockers (ARB). This is an important finding that merits further investigation since it is known that increases in albuminuria even in the low range are associated with increased cardiovascular risk.

\subsection{Renin-angiotensin system blockade}

Inappropriate activation of the RAS blockadeis a hallmark of CKD and DN. In fact, various studies have shown the beneficial role of ACEI and ARB in the treatment of DM in both type 1 and 2 diabetic subjects. Thus, in the Captopril Collaborative Study Group (Lewis et al., 1993), a significant risk reduction in nephropathy progression was shown in type 1 diabetic patients treated with captopril. Also, a meta-analysis of 12 trials in type 1 diabetic patients with microalbuminuria (The ACE Inhibitors in Diabetic Nephropathy Trialist Group, 2001) revealed that the treatment with ACE inhibitor for two years was associated with a $60 \%$ reduction in progression to macroalbuminuria and in threefold increase in regression to normoalbuminuria in comparison with placebo. Mathiesen et al. (1999) has shown that captopril has long lasting (eight years) beneficial renoprotective effect in normotensive patients with type $1 \mathrm{DM}$ and microalbuminuria.

Similar positive results have been demonstrated in type $2 \mathrm{DM}$. Thus, the Microalbuminuria, Cardiovascular and Renal Outcomes - Heart Outcomes Prevention Evaluation (MICROHOPE) study (Gerstein et al., 2000) showed that overt nephropathy was reduced by $24 \%$ in type 2 diabetic patients treated with ramipril, resulting in significant protection against cardiovascular events.

ARBs have also been shown to exhibit significant renoprotective effects. In the IRMA II study, Parving et al. (2001) demonstrated that irbesartan had a renoprotective effect in hypertensive patients with type 2 diabetes and microalbuminuria that was independent of its BP lowering effect. Furthermore, the restoration of normoalbuminuria was more evident in the group receiving irbesartan at a dose of $300 \mathrm{mg}$ daily, as compared to the group receiving 150mg daily. Two other studies, IDNT (Lewis et al., 2001) and RENAAL (Brenner et al., 2001) also used ARBs, but they enrolled patients with higher grade of proteinuria and established renal insufficiency. In both studies, the use of ARBs led to lower levels of proteinuria, lower rates of decline in the GFR and later onset of ESRD than the use of control medications.

By contrast, the use of RAS blockade to lower the increased cardiovascular risk in DN has been disappointing. Although valsartan has been reported to decrease arterial stiffness in patients with DN (Karalliedde et al., 2008), there are no data on hard end-points. In a recent meta-analysis, RAS has been shown to improve cardiovascular outcomes in proteinuric CKD of various types (Balamuthusamy et al., 2008). However in another meta-analysis, 
Sarafidis et al. (2008) failed to show an effect of RAS inhibition on total mortality in DN patients. In conclusion, though there is strong evidence of renoprotection by both ACEIs and ARBs, evidence for cardiovascular protection in DN patients is still lacking.

\subsection{Statins}

Altough the effect of statin use on cardiovascular outcomes in patients with DN has not been extensively studied, there is strong evidence for their effectiveness in both diabetes and in CKD. Their effectiveness in reducing cardiovascular events in diabetic subjects was demonstrated in the Collaborative Atorvastatin Diabetes Study (CARDS) (2004) as well as in meta-analysis of all trials having a diabetes subgroup analysis (Costa et al., 2006). Subgroup analysis of the Cholesterol and Recurrent Events (CARE) (Tonelli et al., 2003), Management of Elevated cholesterol in the primary prevention Group of Adult Japanese (MEGA) (Nakamura et al., 2009) and the Scandinavian Simvastatin Survival Study (4S) (Chonchol et al., 2007) studies have all demonstrated significant cardiovascular protection in CKD patients. A meta-analysis by Strippoli et al. found a reduction in fatal and non-fatal cardiovascular events but not in total mortality. Cochrane reviews have concluded that statins significantly reduced the risk of all-cause and cardiovascular mortality in CKD patients who are not receiving renal replacement therapy (Navaneethan et al., 2009a), but there that was insufficient data on renal transplant patients (Navaneethan et al., 2009b).

Statins also play an important role in renoprotection. Several meta-analyses have been performed to assess the effect of statins on renal function and proteinuria. Fried et al. (2001) performed a meta-analysis with 13 controlled prospective studies and concluded that statin use results in a lower rate of decline in eGFR, although the effect was small. In a second meta-analysis of 27 studies, Sandhu et al. (2006) have shown that statin use resulted in an improvement in eGFR and reduction in proteinuria.

The renoprotective effects of statins are probably secondary to an extension of their modulatory effects on inflammation and oxidant stress (reviewed by Kurukulasuriya et al. (2007)). This is achieved through various mechanisms, mainly:

i. Reduction of generation of reactive oxygen species (ROS)

ii. Suppression of activity of pro-oxidant enzyme systems, mainly NADPH oxidase, xanthine oxidase, oxidase activity of endothelial NO-synthase

iii. Inhibition of Rho expression, resulting in up-regulation of eNOS expression, thereby reducing blood pressure and glomerular injury, together with a decrease in the surface protein endothelin-1 levels. The latter is a potent vasoconstrictor and mitogen, and might play a role in delaying glomerulosclerosis

iv. Interference with LDL oxidation via several mechanisms

v. Inhibition of conversion of monocytes to macrophages by inhibiting their uptake of oxidized LDL.

Among their anti-inflammatory and anti-proliferative effects, statins have been shown to reduce levels of monocyte chemo-attractant protein-1, tumor necrosis factor-alpha (TNF- $\alpha$ ), transforming growth factor-beta (TGF- $\beta$ ), interleukin-6, platelet-derived growth factor, $\mathrm{NFkB}$, and mesangial proteins. These pleiotropic effects distinguish statins from other lipidlowering therapies (e.g. resin binders, fibrates, niacin). All the above mechanisms may also contribute to cardiovascular protective properties of statins, although the main mechanism in this case is thought to be through improving lipid profile particularly lowering of LDL-cholesterol. 


\subsection{Fibrates}

Diabetes mellitus is considered a cardiovascular disease risk equivalent. Consequently, subjects with DN are at higher risk than patients suffering from kidney disease secondary to other aetiologies. Statins decrease coronary event rates to the level equal or even greater to that seen in untreated subjects (Costa et al., 2006). Consequently, there is significant substantial residual risk. This may be partly due to the fact that statins have only limited effectiveness on hypertriglyceridemia and low HDL cholesterol, and they do not normalize the abnormal LDL size-distribution pattern seen in DM.

Peroxisome proliferator-activated receptor (PPAR)alpha agonists, which include fibrates, are more effective in lowering triglycerides, in raising HDL and help to improve ratio of small dense: large buoyant LDL particles (Birjmohun et al., 2005; Tokuno A et al., 2007). Outcome trials of PPARalpha agonists have shown decreased cardiovascular morbidity in patients with diabetes and in those with the metabolic syndrome. In addition, plaque progression is diminished, and there is a decrease in both microvascular (including diabetic nephropathy and retinopathy) and macrovascular complications (reviewed by Staels et al., 2008).

Two trials worth mentioning are the FIELD study and the DAIS study. The FIELD study (Keech et al., 2005) was a multinational, randomised controlled trial with about 10,000 patients with type 2 diabetes mellitus, and not taking statin therapy at study entry. $80 \%$ of the participants were without previous cardiovascular disease. Participants were randomly assigned to micronised fenofibrate $200 \mathrm{mg}$ daily or matching placebo. In the treatment group, the risk of the primary outcome of coronary events was not significantly reduced. However, fenofibrate did reduce nonfatal MI and revascularization procedures by $24 \%$. Furthermore more controls were on statins, which might have attenuated any beneficial effect of fenofibrate. On the other hand, in the DAIS study (DAIS Group, 2001), fenofibrate reduced angiographic progression of CAD in type 2 diabetic patients. Since the data for reducing $\mathrm{CV}$ risk is stronger for statins, fibrates are especially useful as second-line treatment of dyslipidaemia in diabetic patients that cannot tolerate statins. In addition, the combination of fibrates with statins seems to be particularly indicated in diabetic patients with residual hypertriglyceridaemia and/or low HDL despite receiving statin therapy since fibrates help improve overall lipoprotein profile further. However, most fibrates are metabolized by the kidney and, in view of the risk of rhabdomyolysis, careful monitoring and dose adjustment is necessary when statins and fibrates are used as combination treatment in $\mathrm{DN}$ patients.

\subsection{Correction of anaemia}

Anaemia is a common complication of CKD. It is often more severe and occurs at an earlier stage in patients with DN than in patients with CKD secondary to other causes. This anaemia results from erythropoietin (EPO) deficiency. Studies have shown that recombinant human EPO treatment is effective in correcting erythropoietin-deficiency anaemia in patients with $\mathrm{DN}$, besides improving quality of life and well-being in these patients. However, recently, there is increasing concern regarding adverse events caused by EPO treatment when haemoglobin $(\mathrm{Hb})$ concentrations are raised above the recommended target of $11-12 \mathrm{~g} / \mathrm{dL}$, as outlined below.

The Normal Hematocrit Study, Cardiovascular Risk Reduction by Early Anemia Treatment with Epoetin-beta, Correction of Hemoglobin and Outcomes in Renal Insufficiency, and Trial to Reduce Cardiovascular Events with Aranesp Therapy have shown increased risk of 
mortality and/or cardiovascular complications with targeting of a higher $\mathrm{Hb}$ in $\mathrm{CKD}$ patients. There is increasing debate whether it is the higher $\mathrm{Hb}$ level targeted in these trials or the erythropoiesis-stimulating agent (ESA) exposure itself that accounted for the observed increased risk (reviewed by Singh (2010)). This is because, in these trials, achieving a normal or near normal $\mathrm{Hb}$ was associated with improved survival and reduced cardiovascular risk while it seems that it was the 'targeting' of a higher $\mathrm{Hb}$ with ESA that resulted in increased morbidity. However, the results obtained, by their very nature, cannot prove causality. In addition, several study-inherent and methodological limitations must be considered before simply extrapolating the negative findings of these studies into clinical practice. Therefore, until new evidence becomes available from ongoing and future clinical studies, an upper $\mathrm{Hb}$ limit of $12 \mathrm{~g} / \mathrm{dl}$ should not be exceeded.

The increased morbidity with EPO treatment could be explained by its side effects arising from the vascular system. A frequently seen adverse effect of chronic administration of EPO is an increase in arterial BP; postulated mechanisms for EPO-induced hypertension include enhanced vascular reactivity and vasoconstrictor responses. Scalera et al. (2005) have shown that at concentrations corresponding to plasma levels after EPO therapy in patients with chronic renal failure, EPO and darbepoietin a (NESP) increase endothelial elaboration of ADMA and inhibition of NOS by impairing dimethylarginine dimethylaminohydrolase (DDAH) activity. This is probably mediated by oxidative stress. Scalera et al. thus demonstrate a novel mechanism for EPO-induced downregulation of NO synthesis, which may contribute to explain main side effects observed in patients who are treated with EPO. Increased blood viscosity also plays a role in EPO-induced hypertension and increases workload on the heart. In addition, increased whole blood viscosity is an important pathophysiological factor in the development of atherothrombosis and appears to be a strong predictor of CVD. In fact, male blood donors and women of premenopausal age with regular menstruation have shown reduced incidence of cardiovascular events such as myocardial infarction, angina, stroke, and the requirement for procedures such as percutaneous transluminal coronary angioplasty and coronary artery bypass graft compared with non-donors and postmenopausal women, respectively. This is possibly related to decreased whole blood viscosity. Consequently, Jeong et al. (2010) have proposed blood viscosity monitoring as part of cardiovascular risk assessment in the context of anaemia correction with ESAs. As discussed above, EPO may also increase platelet number and activation.

The use of intravenous iron in the correction of anaemia in CKD is also uncertain. The vast majority of patients with CKD are iron-deficient secondary to multiple forms of interference with all phases of iron metabolism. Therefore, iron supplementation is given to CKD patients. Intravenous iron was demonstrated to be superior to oral iron in both hemodialysis and nondialysis-dependent CKD patients. Whereas correction of anemia is effective in reducing oxidative stress and, conceptually cardiovascular risk, intravenous iron could promote cytotoxicity and tissue injury, exacerbate oxidative stress and endothelial dysfunction, as well as inflammation and the progression of both CKD and cardiovascular disease (Garneata, 2008). Clinical judgment is thus necessary in each individual case to diagnose iron deficiency and effectively use intravenous iron.

\subsection{Antiplatelet agents}

Given the high cardiovascular morbidity and mortality associated with DN, it is reasonable to suggest that diabetic subjects suffering from nephropathy should be on regular aspirin 
treatment. In fact, the American Diabetes Association (2004) suggest that diabetic patients $>40$ years old with $\geq 1$ cardiovascular risk factor should be taking prophylactic aspirin while the ESC guidelines (The Task Force on the Use of Antiplatelet Agents in Patients with Atherosclerotic Cardiovascular Disease, 2004) suggest prophylactic aspirin for diabetic patients with 1 -year risk of $\mathrm{CHD}>1.5 \%$.

However, in diabetic patients, aspirin may be less effective than expected. Thus, in the 1031 diabetic patients enrolled in the Primary Prevention Project (Sacco et al., 2003), the effects of aspirin $100 \mathrm{mg}$ daily were surprisingly poor with major vascular events being reduced by only $10 \%$ in diabetic individuals versus $31 \%$ in nondiabetic individuals. This was confirmed in two recent meta-analyses (De Berardis et al., 2009; Stavrakis et al., 2011). The role of aspirin in diabetic patients who are at increased risk because of renal disease remains inadequately investigated. The Primary Prevention Project Investigators suggest that, in diabetes, platelets may be activated through peculiar aspirin-insensitive mechanisms. This may involve hyperproduction of thromboxane from cells and tissues through aspirininsensitive COX-2 pathway, or alternative prostanoid producing mechanisms can be activated by hyperglycaemia or insulin resistance. In addition, there is increased turnover of platelets in DM, possibly suggesting the need for higher doses of aspirin than usual in diabetic patients.

In keeping with aspirin resistance, there is increasing interest in picotamide, a dual inhibitor of thromboxane synthase and thromboxane receptor. In the DAVID study (Neri Serneri et al., 2004), >1200 patients with type 2 DM and established PAD were randomly allocated to picotamide $600 \mathrm{mg}$ or aspirin $320 \mathrm{mg}$. It was demonstrated that picotamide almost halved general mortality compared with aspirin with a significantly lowered relative risk of death (0.55) and reduced, though not significantly, vascular deaths, from $4.1 \%$ to $2.1 \%$. In addition, picotamide caused less bleeding and was better tolerated than aspirin. This study suggests that dual inhibitors of thromboxane synthase and thromboxane receptors may become useful therapies in cardiovascular prevention in diabetic patients. Further studies with picotamide and with other agents of the same class, for example ridogrel and terutroban sodium, are thus desirable.

\subsection{Glycosaminoglycans}

In view that microalbuminuria, the traditional hallmark of $\mathrm{DN}$, is associated with alterations in endothelial permeability secondary to degradation of heparin-sulphate (a glycosaminoglycan component of the intracellular and basement membrane matrix) increasing attention has been focused on the role of glycosaminoglycans in the treatment of $\mathrm{DN}$ and associated cardiovascular complications.

Special attention has been focused on sulodexide, a compound containing $80 \%$ slow-moving heparin and $20 \%$ dermatan sulphate, both of which have been shown to prevent experimental diabetic nephropathy. In the DINAS study (Gambaro et al., 2002), sulodexide significantly decreased albuminuria by $43 \%$ in subjects with DN and the effect persisted at 8-month follow-up with no major adverse events. In addition, sulodexide was effective in both type 1 and type 2 diabetic subjects and it maintained its efficacy during concomitant treatment with ACE inhibitors. The reduction in albuminuria by sulodexide was confirmed in another study by Achour et al. (2005) where albuminuria was significantly decreased at a lower therapeutic dose of sulodexide, independently of diabetes type and baseline presence of micro- or macroalbuminuria. Interestingly, sulodexide has been shown to prevent 
cardiovascular events in non-diabetic survivors of MI (Condorelli et al., 1994) as well as improving the walking performance of PAD patients, some of whom were diabetic.

Therefore, glycosaminoglycans offer a new perspective in the treatment of diabetic nephropathy. However, further research is needed to investigate how and to what extent these agents influence the course of $\mathrm{DN}$ and associated cardiovascular co-morbidities.

\subsection{Lifestyle interventions}

Lifestyle interventions, mainly regular exercise and diet, play an important role in reducing cardiovascular risk in DN patients. Physical exercise is necessary to improve glycaemic control and decrease cardiovascular risk. Interestingly, in a study by Lazarevic et al. (2007) it was shown that six months of aerobic exercise, without any change in the medication, tended to decrease microalbuminuria in type 2 diabetic subjects, independently of any improvement in insulin resistance and oxidative stress parameters. However, further studies are needed to elucidate the mechanisms underlying the beneficial effects of exercise. In addition to restricted calorie and fat intake and adequate fibre intake, dietary manipulation, including protein, phosphorus, and sodium restriction, can potentially exert a cardiovascular protective effect in DN patients by decreasing various cardiovascular risk factors. Diminished sodium intake helps in achieving blood pressure control. Increasesd fibre intake plays an important role in lowering serum cholesterol and improving plasma lipid profile. A low protein may help to reduce proteinuria and in decreasing phosphorus intake and preventing and reversing hyperphosphatemia and secondary hyperparathyroidism. These, in turn, may also help ameliorate insulin sensitivity and metabolic control in diabetic patients, as well as increase the responsiveness to erythropoietin therapy, thus enabling correction of anemia. Protein-restricted diets may have also anti-inflammatory and anti-oxidant properties (Cupisti et al., 2007). Nonetheless, even though dietary restriction may be useful to decrease cardiovascular risk in the DN patient, further studies are needed to assess the effect of renal diets on hard outcomes, as cardiovascular events or mortality.

\section{Conclusion}

The present review underlines the cardiovascular risk to which patients with diabetic nephropathy are exposed and summarizes some of the mechanisms that lead to the increased risk of adverse cardiovascular events. Some of the risk factors are modifiable and can be improved with currently available therapy including aggressive treatment of dyslipidemia, antiplatelet treatment, restriction of protein intake together with adequate exercise. Nonetheless, further research is needed to unravel the pathophysiology underlying cardiovascular complications associated with diabetic nephropathy as well as to investigate novel therapies to enable a decrease in the morbidity and mortality associated with this serious diabetes-related complication. These may require new approaches including the management of the increased oxidative stress and low-grade inflammation.

\section{References}

Achour A, Kacem M, Dibej K, Skhiri H, Bouraoui S, El May M (2005). One year course of oral sulodexide in the management of diabetic nephropathy. J Nephrol 18:568-74. 
Adler AI, Stevens RJ, Manley SE, Bilous RW, Cull CA, Holman RR (2003). Development and progression of nephropathy in type 2 diabetes: The United Kingdom Prospective Diabetes Study (UKPDS 64). Kidney Int 63: 225 -232.

Ahmed S, Cannon CP, Giugliano RP, Murphy SA, Morrow DA, Antman EM, Braunwald E, Gibson CM (2003). The independent and combined risk of diabetes and nonendstage renal impairment in non-ST-segment elevation acute coronary syndromes. J Natl Med Assoc. 2003 Nov; 95(11): 1042-7.

Alebiosu CO, Odusan O, Familoni OB, Jaiyesimi AE (2004). Cardiovascular risk factors in type 2 diabetic Nigerians with clinical diabetic nephropathy. Cardiovasc J S Afr. 2004 May-Jun; 15(3): 124-8.

Alebiosu CO, Odusan O, Jaiyesimi A (2008). Morbidity in relation to stage of diabetic nephropathy in type 2 diabetic patients. Int J Cardiol. 2008 Dec 17; 131(1): 10512.

Alwakeel JS, Al-Suwaida A, Isnani AC, Al-Harbi A, Alam A (2009). Concomitant macro and microvascular complications in diabetic nephropathy. Saudi J Kidney Dis Transpl. 2009 May; 20(3): 402-9.

Amann K, Ritz E, Wiest G, Klaus G, Mall G (1994). A role of parathyroid hormone for the activation of cardiac fibroblasts in uremia. J Am Soc Nephrol 4: 1814-1819.

Amann K, Wanner C, Ritz E (2006). Cross-talk between the kidney and the cardiovascular system. J Am Soc Nephrol. 2006 Aug; 17(8): 2112-9.

American Diabetes Association (2004). Aspirin therapy in diabetes. Diabetes Care 27: S72-3.

American Diabetes Association Position Statement (2004). Hypertension management in adults with diabetes. Diabetes Care 27:S65-S67

Anavekar NS, Gans DJ, Berl T, Rohde RD, Cooper W, Bhaumik A, Hunsicker LG, Rouleau JL, Lewis JB, Rosendorff C, Porush JG, Drury PL, Esmatjes E, Raz I, Vanhille P, Locatelli F, Goldhaber S, Lewis EJ, Pfeffer MA (2004). Predictors of cardiovascular events in patients with type 2 diabetic nephropathy and hypertension: A case for albuminuria. Kidney Int. 66 (suppl 92): S50-S55.

Anavekar NS, Solomon SD, McMurray JJ, Maggioni A, Rouleau JL, Califf R, White H, Kober L, Velazquez E, Pfeffer MA (2008). Comparison of renal function and cardiovascular risk following acute myocardial infarction in patients with and without diabetes mellitus. Am J Cardiol. 2008 Apr 1;101(7):925-9.

Anderson S, Brenner BM (1988). Influence of antihypertensive therapy on development and progression of diabetic glomerulopathy. Diabetes Care 11: 846-9.

Aso Y, Yoshida N, Okumura K, Wakabayashi S, Matsutomo R, Takebayashi K, Inukai T (2004). Coagulation and inflammation in overt diabetic nephropathy: association with hyperhomocysteinemia. Clin Chim Acta. 2004 Oct; 348(1-2): 139-45.

Astrup AS, Tarnow L, Rossing P, Hansen BV, Hilsted J, Parving HH (2006). Cardiac autonomic neuropathy predicts cardiovascular morbidity and mortality in type 1 diabetic patients with diabetic nephropathy. Diabetes Care 2006 Feb; 29(2): 334-9.

Astrup AS, Nielsen FS, Rossing P, Ali S, Kastrup J, Smidt UM, Parving HH (2007). Predictors of mortality in patients with type 2 diabetes with or without diabetic nephropathy: a follow-up study. J Hypertens 2007 Dec; 25(12):2479-85. 
Block GA, Hulbert-Shearon TE, Levin NW, Port FK (1998). Association of serum phosphorus and calcium $\mathrm{x}$ phosphate product with mortality risk in chronic hemodialysis patients: A national study. Am J Kidney Dis 31: 607-617.

Balamuthusamy S, Srinivasan L, Verma M, Adigopula S, Jalandhara N, Hathiwala S, Smith E (2008). Renin angiotensin system blockade and cardiovascular outcomes in patients with chronic kidney disease and proteinuria: a meta-analysis. Am Heart J. 2008 May; 155(5): 791-805.

Beck MO, Silveiro SP, Friedman R, Clausell N, Gross JL (1999). Asymptomatic coronary artery disease is associated with cardiac autonomic neuropathy and diabetic nephropathy in type 2 diabetic patients. Diabetes Care 1999 Oct; 22(10): 1745-7.

Berl T, Hunsicker LG, Lewis JB, Pfeffer MA, Porush JG, Rouleau JL, Drury PL, Esmatjes E, Hricik D, Parikh CR, Raz I, Vanhille P, Wiegmann TB, Wolfe BM, Locatelli F, Goldhaber SZ, Lewis EJ; Irbesartan Diabetic Nephropathy Trial. Collaborative Study Group (2003). Cardiovascular outcomes in the Irbesartan Diabetic Nephropathy Trial of patients with type 2 diabetes and overt nephropathy. Ann Intern Med 138: 542-9.

Bianchi C, Penno G, Pancani F, Civitelli A, Piaggesi A, Caricato F, Pellegrini G, Del Prato S, Miccoli R (2007). Non-traditional cardiovascular risk factors contribute to peripheral arterial disease in patients with type 2 diabetes. Diabetes Res Clin Pract. 2007 Nov; 78(2):246-53. Epub 2007 May 10.

Birjmohun RS, Hutten BA, Kastelein JJ, Stroes ES (2005). Efficacy and safety of high-density lipoprotein cholesterol-increasing compounds: a meta-analysis of randomized controlled trials. J Am Coll Cardiol 45: 185-197.

Bouchi R, Babazono T, Nyumura I, Toya K, Hayashi T, Ohta M, Hanai K, Kiuchi Y, Suzuki $\mathrm{K}$, Iwamoto $\mathrm{Y}$ (2009). Is a reduced estimated glomerular filtration rate a risk factor for stroke in patients with type 2 diabetes? Hypertens Res. 2009 May; 32(5): 381-6. Epub 2009 Mar 27.

Bouchi R, Babazono T, Yoshida N, Nyumura I, Toya K, Hayashi T, Hanai K, Tanaka N, Ishii A, Iwamoto Y (2010). Relationship between chronic kidney disease and silent cerebral infarction in patients with Type 2 diabetes. Diabet Med. 2010 May; 27(5): $538-43$.

Boulanger CM, Amabile N, Guérin AP, Pannier B, Leroyer AS, Mallat CN, Tedgui A, London GM (2007). In vivo shear stress determines circulating levels of endothelial microparticles in end-stage renal disease. Hypertension. 2007 Apr; 49(4): 902-8.

Brenner BM, Garcia DL, Anderson (1988). Glomeruli and blood pressure. Less of one, more the other? Am J Hypertens 1: 335-347.

Brenner BM, Cooper ME, De Zeeuw D, Mitch WE, Parving HH, Remuzzi G, Snapinn SM, Zhang ZX, Shahinfar S, RENAAL Study (2001). Effects of losartan on renal and cardiovascular outcomes in patients with type 2 diabetes and nephropathy. $N$ Engl J Med. 345: 861-869.

Busch M, Franke S, Wolf G, Brandstadt A, Ott U, Gerth J, Hunsicker LG, Stein G; Collaborative Study Group (2006). The advanced glycation end product N(epsilon)carboxymethyllysine is not a predictor of cardiovascular events and renal outcomes 
in patients with type 2 diabetic kidney disease and hypertension. Am J Kidney Dis 48: 571-9.

Busch M, Franke S, Rüster C, Wolf G (2010). Advanced glycation end-products and the kidney. Eur J Clin Invest. 2010 Aug; 40(8): 742-55.

Chonchol M, Cook T, Kjekshus J, Pedersen TR, Lindenfeld J (2007). Simvastatin for secondary prevention of all-cause mortality and major coronary events in patients with mild chronic renal insufficiency. Am J Kidney Dis. 2007 Mar; 49(3): 373-82.

Clausen P, Jacobsen P, Rossing K, Jensen JS, Parving HH, Feldt-Rasmussen B (2000). Plasma concentrations of VCAM-1 and ICAM-1 are elevated in patients with Type 1 diabetes mellitus with microalbuminuria and overt nephropathy. Diabet Med. 2000 Sep; 17(9): 644-9.

Collins AJ, Li S, Gilbertson DT, Liu J, Chen SC, Herzog CA (2003). Chronic kidney disease and cardiovascular disease in the Medicare population. Kidney Int Suppl. 87: S24S31.

Compendium of ESC Guidelines 2007, Section III: Diabetic Heart Disease. Lippincott Williams and Wilkins; 2007. pp. 33-52

Condorelli M, Chiarello M, Dagianti A, Penco M, Dalla Volta S, Pengo V, Schivazappa L, Mattioli G, Mattioli AV, Brusoni B, et al. (1994). IPO-V2: a prospective multicenter, randomized, comparative clinical investigation of effects of sulodexide in preventing cardiovascular accidents in the first year after acute myocardial infarction. J Am Coll Cardiol 23: 27-34.

Corrêa Leite ML (2011). Fibrinogen, hematocrit, platelets in mild kidney dysfunction and the role of uric acid: an Italian male population study. Clin Appl Thromb Hemost. 2011 Feb; 17(1): 58-65. Epub 2009 Oct 13.

Costa J, Borges M, David C, Vaz Carneiro (2006). Efficacy of lipid lowering drug treatment for diabetic and non-diabetic patients: meta-analysis of randomised controlled trials. BMJ 2006 May 13; 332(7550): 1115-24. Epub 2006 Apr 3

Cupisti A, Aparicio M, Barsotti G (2007). Potential benefits of renal diets on cardiovascular risk factors in chronic kidney disease patients. Ren Fail. 29(5): 529-34.

DAIS Group (2001). Effect of fenofibrate on progression of coronary-artery disease in type 2 diabetes: the Diabetes Atherosclerosis Intervention Study, a randomised study. Lancet 2001 Mar 24; 357(9260): 905-10.

Davis WA, Norman PE, Bruce DG, Davis TM (2006). Predictors, consequences and costs of diabetes-related lower extremity amputation complicating type 2 diabetes: the Fremantle Diabetes Study. Diabetologia. 2006 Nov; 49(11): 2634-41.

De Berardis G, Sacco M, Strippoli GF, Pellegrini F, Graziano G, Tognoni G, Nicolucci A (2009). Aspirin for primary prevention of cardiovascular events in people with diabetes: meta-analysis of randomised controlled trials. BMJ 2009 Nov 6; 339:b4531.

Deckert T, Feldt-Rasmussen B, Borch-Johnsen K, Jensen T, Kofoed-Enevoldsen A (1989). Albuminuria reflects widespread vascular damage. The Steno hypothesis. Diabetologia 32: 219-226.

Dinneen SF, Gerstein HC (1997). The association of microalbuminuria and mortality in noninsulin-dependent diabetes mellitus: a systematic overview of the literature. Arch Intern Med. 157(13): 1413-1418. 
Fava S, Azzopardi J, Watkins PJ, Hattersley AT (2001). Adult height and proteinuria in type 2 diabetes. Nephrol Dial Transplant. 2001 Mar; 16(3): 525-8.

Fliser D (2010). Perspectives in renal disease progression: the endothelium as a treatment target in chronic kidney disease. J Nephrol. 2010 Jul-Aug; 23(4): 369-76.

Foley RN, Murray AM, Li S, Herzog CA, McBean AM, Eggers PW, Collins AJ (2005). Chronic kidney disease and the risk for cardiovascular disease, renal replacement, and death in the United States Medicare population, 1998 to 1999. J Am Soc Nephrol. 2005 Feb; 16(2): 489-495.

Fox CS, Larson MG, Vasan RS, Guo CY, Parise H, Levy D, Leip EP, O'donnell CJ, D'Agostino RB Sr, Benjamin EJ (2006). Cross-sectional association of kidney function with valvular and annular calcification: the Framingham heart study. J Am Soc Nephrol. 2006 Feb; 17(2): 521-7. Epub 2005 Dec 28.

Gambaro G, Kinalska I, Oksa A, Pont'uch P, Hertlová M, Olsovsky J, Manitius J, Fedele D, Czekalski S, Perusicová J, Skrha J, Taton J, Grzeszczak W, Crepaldi G (2002). Oral sulodexide reduces albuminuria in microalbuminuric type 1 and type 2 diabetic patients: the Di.N.A.S. randomized trial. J Am Soc Nephrol 13:161525.

Garneata L (2008). Intravenous iron, inflammation, and oxidative stress: is iron a friend or an enemy of uremic patients? J Ren Nutr. 2008 Jan; 18(1): 40-5.

Gerstein HC, Yusuf S, Mann JFE, et al (2000). Effects of ramipril on cardiovascular and microvascular outcomes in people with diabetes mellitus: results of the HOPE study and MICRO-HOPE substudy. Lancet 355: 253-259.

Gerstein HC, Mann JF, Yi Q, Zinman B, Dinneen SF, Hoogwerf B, Hallé JP, Young J, Rashkow A, Joyce C, Nawaz S, Yusuf S; HOPE Study Investigators (2001). Albuminuria and risk of cardiovascular events, death, and heart failure in diabetic and nondiabetic individuals. JAMA 286(4): 421-426.

Go AS, Chertow GM, Fan D, McCulloch CE, Hsu CY (2004). Chronic kidney disease and the risks of death, cardiovascular events, and hospitalization. N Engl J Med. 351(13): 1296-1305.

Gouverneur M, Berg B, Nieuwdorp M, Stroes E, Vink H (2006). Vasculoprotective properties of the endothelial glycocalyx: Effects of fluid shear stress. J Intern Med 259: 393400.

Groop L, Ekstrand A, Forsblom C and Widen E, Groop P-H, Teppo A-M, Eriksson J (1993): Insulin resistance, hypertension and microalbuminuria in patients with type 2 (non-insulin-dependent) diabetes mellitus. Diabetologia 36: 642-7

Henry CB, Duling BR (1999). Permeation of the luminal capillary glycocalyx is determined by hyaluronan. Am J Physiol 277: H508-H514.

Hernández C, Chacón P, Martí R, García-Pascual L, Mesa J, Simó R (2000). Relationship of lipoprotein(a) and its phenotypes with the albumin excretion rate in diabetic patients: a multivariate analysis. Nephron 2000 May; 85(1): 27-33.

Hsieh MC, Tien KJ, Perng DS, Hsiao JY, Chang SJ, Liang HT, Chen HC, Tu ST (2009). Diabetic nephropathy and risk factors for peripheral artery disease in Chinese with type 2 diabetes mellitus. Metabolism 2009 Apr; 58(4): 504-9. 
Hsu CY, McCulloch CE, Darbinian J, Go AS, Irbarren C (2005). Elevated blood pressure and risk of end-stage renal disease in subjects without baseline kidney disease. Arch Intern Med 165: 923-925.

Hummel D, Raff U, Schwarz TK, Schneider MP, Schmieder RE, Schmidt BM (2010). Dihydropyridine calcium antagonists are associated with increased albuminuria in treatment-resistant hypertensives. J Nephrol 2010 Sep-Oct; 23(5):563-8.

Ismail N, Cornell S. Epidemiology of type 2 diabetes and diabetic nephropathy in different ethnicities. In Nephropathy in Type 2 Diabetes, Ritz E, Rychlik I (eds). Oxford University Press: Oxford, 1999; 11-24.

Jeong SK, Cho YI, Duey M, Rosenson RS (2010). Cardiovascular risks of anemia correction with erythrocyte stimulating agents: should blood viscosity be monitored for risk assessment? Cardiovasc Drugs Ther. 2010 Apr; 24(2): 151-60.

Jones CA, Krolewski AS, Rogus J, Xue JL, Collins A, Warram JH (2005). Epidemic of endstage renal disease in people with diabetes in the United States population: Do we know the cause? Kidney Int 67: $1684-1691$.

Kang D-H, Park S-K, Lee I-K, Johnson RJ (2005). Uric acid-induced C-reactive protein expression: Implication on cell proliferation and nitric oxide production of human vascular cells. J Am Soc Nephrol 16(12): 3553-3562.

Karalliedde J, Smith A, DeAngelis L, Mirenda V, Kandra A, Botha J, Ferber P, Viberti G (2008). Valsartan improves arterial stiffness in type 2 diabetes independently of blood pressure lowering. Hypertension. 2008 Jun; 51(6): 1617-23. Epub 2008 Apr 21.

Keech A, Simes RJ, Barter P, Best J, Scott R, Taskinen MR, Forder P, Pillai A, Davis T, Glasziou P, Drury P, Kesäniemi YA, Sullivan D, Hunt D, Colman P, d'Emden M, Whiting M, Ehnholm C, Laakso M; FIELD study investigators (2006). Effects of long-term fenofibrate therapy on cardiovascular events in 9795 people with type 2 diabetes mellitus (the FIELD study): randomised controlled trial. Lancet. 2005 Nov 26; 366(9500): 1849-61. Erratum in: Lancet. 2006 Oct 21;368(9545):1415. Lancet. 2006 Oct 21; 368(9545):1420.

Khosla UM, Zharikov S, Finch JL, Nakagawa T, Roncal C, Mu W, Krotova K, Block ER, Prabhakar S, Johnson RJ (2005). Hyperuricemia induces endothelial dysfunction. Kidney Int. 67(5): 1739-1742.

Kidney Disease Outcomes Quality Initiative (K/DOQI) (2004). K/DOQI clinical practice guidelines on hypertension and antihypertensive agents in chronic kidney disease. Am J Kidney Dis. 2004 May; 43(5)(suppl 1): S1-S290.

Kielstein JT, Böger RH, Bode-Böger SM, Schaffer J, Barbey M, Koch KM, Frölich JC (1999). Asymmetric dimethylarginine plasma concentrations differ in patients with endstage renal disease: relationship to treatment method and atherosclerotic disease. $J$ Am Soc Nephrol 10: 594-600.

Klausen K, Borch-Johnsen K, Feldt-Rasmussen B, Jensen G, Clausen P, Scharling H, Appleyard M, Jensen JS (2004). Very low levels of microalbuminuria are associated with increased risk of coronary heart disease and death independently of renal function, hypertension, and diabetes. Circulation 2004 Jul 6; 110(1):32-35.

Krzyzanowska K, Mittermayer F, Shnawa N, Hofer M, Schnabler J, Etmüller Y, Kapiotis S, Wolzt M, Schernthaner G (2007). Asymmetrical dimethylarginine is related to renal function, chronic inflammation and macroangiopathy in patients with Type 2 diabetes and albuminuria. Diabet Med. 2007 Jan; 24(1): 81-6. 
Lazarevic G, Antic S, Vlahovic P, Djordjevic V, Zvezdanovic L, Stefanovic V (2007). Effects of aerobic exercise on microalbuminuria and enzymuria in type 2 diabetic patients. Ren Fail 29(2): 199-205.

Leiper JM, Vallance P (2006). The synthesis and metabolism of asymmetric dimethylarginine (ADMA). Eur J Clin Pharmacol 62: 33-38.

Levey AS, Coresh J, Balk E, Kausz AT, Levin A, Steffes MW, Hogg RJ, Perrone RD, Lau J, Eknoyan G; National Kidney Foundation (2003). National Kidney Foundation practice guidelines for chronic kidney disease: evaluation, classification, and stratification [published correction appears in Ann Intern Med. 2003; 139(7):605]. Ann Intern Med. 2003; 139(2): 137-147.

Lewis EJ, Hunsicker LG, Bain RP, Rohde RD (1993). The effect of angiotensin converting enzyme inhibition on diabetic nephropathy. N Engl J Med 329: 1456-1462

Lewis EJ, Hunsicker LG, Clarke WR, Berl T, Pohl MA, Lewis JB, Ritz E, Atkins RC, Rohde R, Raz I, Collaborative Study Group (2001). Renoprotective effect of the angiotensinreceptor antagonist irbesartan in patients with nephropathy due to type 2 diabetes. N Engl J Med 345: 851-860.

Li J, Luo Y, Xu Y, Yang J, Zheng L, Hasimu B, Yu J, Hu D (2007). Risk factors of peripheral arterial disease and relationship between low ankle-brachial index and mortality from all-cause and cardiovascular disease in Chinese patients with type 2 diabetes. Circ J. 2007 Mar; 71(3): 377-81.

Lindsay RS, Little J, Jaap AJ, Padfield PL, Walker JD, Hardy KJ (1999). Diabetic nephropathy is associated with an increased familial risk of stroke. Diabetes Care 1999 Mar; 22(3): 422-5.

Lindsey JB, Cipollone F, Abdullah SM, McGuire DK (2009). Receptor for advanced glycation end-products (RAGE) and soluble RAGE (sRAGE): cardiovascular implications. Diab Vasc Dis Res. 2009 Jan; 6(1): 7-14.

Liu H, Shi H, Yu J, Chen F, Jiang Q, Hu D (2010). Is Chronic Kidney Disease Associated with a High Ankle Brachial Index in Adults at High Cardiovascular Risk? J Atheroscler Thromb. 2010 Nov 25. [Epub ahead of print]

Magri CJ, Calleja N, Buhagiar G, Fava S, Vassallo J. Ankle-brachial index in a type 2 diabetic population with proliferative retinopathy: associated risk factors and complications. Int Angiology. In press.

Mann JFE, Yi QL, Gerstein HC (2004). Albuminuria as a predictor of cardiovascular and renal outcomes in people with known atherosclerotic cardiovascular disease. Kidney Int 66: S59-S62

Mathiesen ER, Borch Johnsen K, Jensen DV, Deckert T (1989). Improved survival in patients with diabetic nephropathy. Diabetologia 32: 884-6.

Mathiesen R, Hommel E, Hansen HP, Smidt UM, Parving HH (1999).Randomised controlled trial of long term efficacy of captopril on preservation of kidney function in normotensive patients with insulin dependent diabetes and microalbuminuria. BMJ 319: 24-25.

Mattock MB, Barnes DJ, Viberti G, Keen H; Burt D, Hughes JM; Fitzgerald AP, Sandhu B, Jackson PG (1998). Microalbuminuria and coronary heart disease in NIDDM: an incidence study. Diabetes 47: 1786-1792

McQuarrie EP, Patel RK, Mark PB, Delles C, Connell J, Dargie HJ, Steedman T, Jardine AG (2010). Association between proteinuria and left ventricular mass index: a cardiac 
MRI study in patients with chronic kidney disease. Nephrol Dial Transplant. 2010 Jul 12. [Epub ahead of print]

Miettinen H, Haffner SM, Lehto S, Rönnemaa T, Pyörälä K, Laakso M (1996). Proteinuria predicts stroke and other atherosclerotic vascular disease events in nondiabetic and non-insulin-dependent diabetic subjects. Stroke 27(11): 2033-2039.

Miyazato J, Horio T, Takiuchi S, Kamide K, Sasaki O, Nakamura S, Nakahama H, Inenaga T, Takishita S, Kawano Y (2005). Left ventricular diastolic dysfunction in patients with chronic renal failure: impact of diabetes mellitus. Diabet Med. 2005 Jun; 22(6): 730-6.

Mogensen CE (1982). Long-term antihypertensive treatment inhibiting progression of diabetic nephropathy. BMJ 285: 685-8.

Mogensen CE, Christensen CK, Vittinghus E (1983). The stages in diabetic renal disease: with emphasis on the stage of incipient diabetic nephropathy. Diabetes 32 (Suppl. 2): $64-78$

Molitch ME, Rutledge B, Steffes M, Cleary P (2006). Renal insufficiency in the absence of albuminuria among adults with Type 1 diabetes in the Diabetes Control and Complications Trial (DCCT)/Epidemiology of Diabetes Interventions and Complications (EDIC) Study. ADA Annual Meeting 2006 (Abstract 23-OR).

Mostaza JM, Suarez C, Manzano L, Cairols M, García-Iglesias F, Sanchez-Alvarez J, Ampuero J, Godoy D, Rodriguez-Samaniego A, Sanchez-Zamorano MA; MERITO Study Group (2006). Relationship between ankle-brachial index and chronic kidney disease in hypertensive patients with no known cardiovascular disease. J Am Soc Nephrol. 2006 Dec; 17(12 Suppl 3): S201-5.

Nag S, Bilous R, Kelly W, Jones S, Roper N, Connolly V (2007). All-cause and cardiovascular mortality in diabetic subjects increases significantly with reduced estimated glomerular filtration rate (eGFR): 10 years' data from the South Tees Diabetes Mortality study. Diabet Med. 2007 Jan; 24(1): 10-7

Nakamura H, Mizuno K, Ohashi Y, Yoshida T, Hirao K, Uchida Y; MEGA Study Group (2009). Pravastatin and cardiovascular risk in moderate chronic kidney disease. Atherosclerosis. 2009 Oct; 206(2): 512-7. Epub 2009 Apr

Navaneethan SD, Pansini F, Perkovic V, Manno C, Pellegrini F, Johnson DW, Craig JC, Strippoli GF (2009a). HMG CoA reductase inhibitors (statins) for people with chronic kidney disease not requiring dialysis. Cochrane Database Syst Rev. 2009 Apr 15; (2): CD007784.

Navaneethan SD, Perkovic V, Johnson DW, Nigwekar SU, Craig JC, Strippoli GF (2009b). HMG CoA reductase inhibitors (statins) for kidney transplant recipients. Cochrane Database Syst Rev. 2009 Apr 15; (2): CD005019.

Navarro JF, Mora C, Gómez M, Muros M, López-Aguilar C, García J (2008). Influence of renal involvement on peripheral blood mononuclear cell expression behaviour of tumour necrosis factor-alpha and interleukin-6 in type 2 diabetic patients. Nephrol Dial Transplant. 2008 Mar; 23(3): 919-26. Epub 2007 Oct 2.

Nelson RG, Pettitt DJ, Baird HR, Charles MA, Liu QZ, Bennett PH, Knowler WC (1993): Prediabetic blood pressure predicts urinary albumin excretion after the onset of type 2 (non-insulin-dependent) diabetes mellitus in Pima Indians. Diabetologia 36: 9981001. 
Nelson RG, Pettitt DJ, de Courten MP, Hanson RL, Knowler WC, Bennett PH (1996). Parental hypertension and proteinuria in Pima Indians with NIDDM. Diabetologia. 1996 Apr; 39(4): 433-8

Nemes A, Takács R, Gavallér H, Várkonyi TT, Wittmann T, Forster T, Lengyel C (2010). Correlations between aortic stiffness and parasympathetic autonomic function in healthy volunteers. Can J Physiol Pharmacol. 2010 Dec; 88 (12): 1166-71.

Neri Serneri GC, Coccheri S, Marubini E, et al., on behalf of the Drug evaluation in Atherosclerotic Vascular disease in Diabetics (DAVID) Study Group (2004). Picotamide, a combined inhibitor of thromboxane A2 synthase and receptor, reduces 2-year mortality in diabetics with peripheral arterial disease: the DAVID Study. Eur Heart J 25: 1845-52.

Nin JW, Jorsal A, Ferreira I, Schalkwijk CG, Prins MH, Parving HH, Tarnow L, Rossing P, Stehouwer CD (2010). Higher plasma soluble receptor for advanced glycation end products (sRAGE) levels are associated with incident cardiovascular disease and all-cause mortality in Type 1 diabetes: a 12-year follow-up study. Diabetes 59(8), 2027-2032.

Nishimura M, Hashimoto T, Kobayashi H, Fukuda T, Okino K, Yamamoto N, Nakamura N, Yoshikawa T, Takahashi H, Ono T (2004). Association between cardiovascular autonomic neuropathy and left ventricular hypertrophy in diabetic haemodialysis patients. Nephrol Dial Transplant. 2004 Oct; 19(10): 2532-8. Epub 2004 Jul 13.

Noordzij MJ, Lefrandt JD, Smit AJ (2008). Advanced glycation end products in renal failure: an overview. J Ren Care. 2008 Dec ;34(4): 207-12.

O'Hare AM, Glidden DV, Fox CS, Hsu CY (2004). High prevalence of peripheral arterial disease in persons with renal insufficiency: results from the National Health and Nutrition Examination Survey 1999-2000. Circulation 109: 320-323.

Ots M, Troy JL, Rennke HG, Mackenzie HS, Brenner BM (2004). Impact of the supplementation of kidney mass on blood pressure and progression of kidney disease. Nephrol Dial Transplant. 2004 Feb; 19(2): 337-41.

Parving HH, Hommel E (1989). Prognosis in diabetic nephropathy. BMJ 299: 230-3.

Parving HH, Smidt UM, Hommel E, Mathiesen ER, Rossing P, Nielsen F, Gall MA (1993). Effective antihypertensive treatment postpones renal insufficiency in diabetic nephropathy. Am J Kidney Dis 22: 188-95.

Parving HH, Lehnert H, Bröchner-Mortensen J, Gomis R, Andersen S, Arner P; Irbesartan in Patients with Type 2 Diabetes and Microalbuminuria Study Group (2001). The effect of irbesartan on the development of diabetic nephropathy in patients with type 2 diabetes. $N$ Engl J Med 345: 870-876.

Pettersson-Fernholm K, Karvonen MK, Kallio J, Forsblom CM, Koulu M, Pesonen U, Fagerudd JA, Groop PH; FinnDiane Study Group (2004). Leucine 7 to proline 7 polymorphism in the preproneuropeptide $\mathrm{Y}$ is associated with proteinuria, coronary heart disease, and glycemic control in type 1 diabetic patients. Diabetes Care 2004 Feb; 27(2): 503-9.

Ragosta M, Samady H, Isaacs RB, Gimple LW, Sarembock IJ, Powers ER (2004). Coronary flow reserve abnormalities in patients with diabetes mellitus who have end-stage renal disease and normal epicardial coronary arteries. Am Heart J 2004 Jun; 147(6): 1017-23. 
Ritz E, Stefanski A (1996). Diabetic nephropathy in type 2 diabetes. Am J Kidney Dis 27: 167194.

Ritz E, Orth SR (1999a). Nephropathy in patients with type 2 diabetes mellitus. N Engl J Med 341: 1127-1133.

Ritz E, Rychlik I, Locatelli F, Halimi S (1999b). End-stage renal failure in type 2 diabetes: a medical catastrophe of worldwide dimensions. Am J Kidney Dis 34: 795-808.

Ritz E (2010). Hypertension and kidney disease. Clin Nephrol. 2010 Nov; 74 Suppl 1: S39-43.

Rossing P, Tamow L, Nielson FS, Boelskifte S, Brenner BM, Parving HH (1995). Short stature and diabetic nephropathy. Br Med J 310: 296-297.

Sacco M, Pellegrini F, Roncaglioni MC, et al. on behalf of the PPP Collaborative Group (2003). Primary prevention of cardiovascular events with low-dose aspirin and vitamin E in type 2 diabetic patients: results of the Primary Prevention Project (PPP) trial. Diabetes Care 26: 3264-72.

Sarafidis PA, Stafylas PC, Kanaki AI, Lasaridis AN (2008). Effects of renin-angiotensin system blockers on renal outcomes and all-cause mortality in patients with diabetic nephropathy: an updated meta-analysis. Am J Hypertens. 2008 Aug;21(8):922-9. Epub 2008 Jun 5.

Saxena AB, Myers BD, Derby G, Blouch KL, Yan J, Ho B, Tan JC (2006). Adaptive hyperfiltration in the aging kidney after contralateral nephrectomy. Am J Physiol Renal Physiol. 2006 Sep; 291(3):F629-34. Epub 2006 Mar 8.

Scalera F, Kielstein JT, Martens-Lobenhoffer J, Postel SC, Täger M, Bode-Böger SM (2005). Erythropoietin increases asymmetric dimethylarginine in endothelial cells: role of dimethylarginine dimethylaminohydrolase. J Am Soc Nephrol. 2005 Apr; 16(4): 8928. Epub 2005 Feb 23.

Schiffrin EL, Touyz RM (2004). From bedside to bench to bedside: role of renin-angiotensinaldosterone system in remodeling of resistance arteries in hypertension. Am J Physiol Heart Circ Physiol 287: H435-H446

Schnabel R, Blankenberg S, Lubos E, Lackner KJ, Rupprecht HJ, Espinola-Klein C, Jachmann N, Post F, Peetz D, Bickel C, Cambien F, Tiret L, Münzel T (2005). Asymmetric dimethylarginine and the risk of cardiovascular events and death in patients with coronary artery disease: results from the AtheroGene Study. Circ Res 97: e53- 59.

Schukla N, Thompson CS, Angelini GD, Mikhailidis DP, Jeremy JY (2002). Homocysteine enhances impairment of endothelium-dependent relaxation and guanosine cyclic monophosphate formation in aortae from diabetic rabbits. Diabetologia 45:1325-31.

Shoji T, Emoto M, Kawagishi T, Kimoto E, Yamada A, Tabata T, Ishimura E, Inaba M, Okuno Y, Nishizawa Y (2001). Atherogenic lipoprotein changes in diabetic nephropathy. Atherosclerosis. 2001 Jun; 156(2): 425-33.

Singh AK (2010). What is causing the mortality in treating the anemia of chronic kidney disease: erythropoietin dose or hemoglobin level? Curr Opin Nephrol Hypertens 2010 Sep; 19(5): 420-4.

Sobotka PA, Liss HP, Vinik AI (1986). Impaired hypoxic ventilatory drive in diabetic patients with autonomic neuropathy. J Clin Endocrinol Metab 62:658-663.

Soedamah-Muthu SS, Chaturvedi N, Teerlink T, Idzior-Walus B, Fuller JH, Stehouwer CD; Eurodiab ProspectivE Complications Study Group (2005). Plasma homocysteine and microvascular and macrovascular complications in type 1 diabetes: a crosssectional nested case-control study. J Intern Med. 2005 Nov ;258(5): 450-9. 
Staels B, Maes M, Zambon A (2008). Fibrates and future PPARalpha agonists in the treatment of cardiovascular disease. Nat Clin Pract Cardiovasc Med. 2008 Sep; 5(9): 542-53. Epub 2008 Jul 15.

Stavrakis S, Stoner JA, Azar M, Wayangankar S, Thadani U (2011). Low-dose aspirin for primary prevention of cardiovascular events in patients with diabetes: a metaanalysis. Am J Med Sci. 2011 Jan; 341(1): 1-9.

Strippoli GF, Navaneethan SD, Johnson DW, Perkovic V, Pellegrini F, Nicolucci A, Craig JC (2008). Effects of statins in patients with chronic kidney disease: meta-analysis and meta-regression of randomised controlled trials. BMJ 2008 Mar 22; 336(7645): 64551. Epub 2008 Feb 25.

Surdacki A, Nowicki M, Sandmann J, Tsikas D, Boeger RH, Bode-Boeger SM, KruszelnickaKwiatkowska O, Kokot F, Dubiel JS, Froelich JC (1999). Reduced urinary excretion of nitric oxide metabolites and increased plasma levels of asymmetric dimethylarginine in men with essential hypertension. J Cardiovasc Pharmacol 33: 652-658.

Suzuki E, Egawa K, Nishio Y, Maegawa H, Tsuchiya M, Haneda M, Yasuda H, Morikawa S, Inubushi T, Kashiwagi A (2003). Prevalence and major risk factors of reduced flow volume in lower extremities with normal ankle-brachial index in Japanese patients with type 2 diabetes. Diabetes Care 2003 Jun; 26(6): 1764-9.

Suzuki K, Kato K, Hanyu O, Nakagawa O, Aizawa Y (2001). Left ventricular mass index increases in proportion to the progression of diabetic nephropathy in Type 2 diabetic patients. Diabetes Res Clin Pract. 2001 Dec; 54(3): 173-80.

Szeto CC, Chow KM, Poon PY, Kwan BC, Li PK (2008). Peroxisome proliferator-activated receptor-gamma gene polymorphism and risk of cardiovascular disease in patients with diabetic nephropathy. Am J Nephrol. 2008; 28(5): 715-22. Epub 2008 Apr 17.

Takenaka T, Sato T, Hoshi H, Kato N, Sueyoshi K, Tsuda M, Watanabe Y, Takane H, Ohno Y, Suzuki H (2010). Height constitutes an important predictor of mortality in endstage renal disease. Cardiol Res Pract. 2010 Nov 11; 2011: 242353.

USRDS 2004 Annual Data Report, Bethesda, National Institutes of Health, National Institute of Diabetes and Digestive and Kidney Diseases, 2004.

Tarnow L, Hovind P, Teerlink T, Stehouwer CD, Parving HH (2004). Elevated plasma asymmetric dimethylarginine as a marker of cardiovascular morbidity in early diabetic nephropathy in type 1 diabetes. Diabetes Care 27: 765-769.

Tessari P, Kiwanuka E, Barazzoni R, Vettore M, Zanetti M (2006). Diabetic nephropathy is associated with increased albumin and fibrinogen production in patients with type 2 diabetes. Diabetologia 2006 Aug; 49(8): 1955-61. Epub 2006 May 16.

The ACE Inhibitors in Diabetic Nephropathy Trialist Group (2001). Should all patients with type 1 diabetes mellitus and microalbuminuria receive angiotensin-converting enzyme inhibitors? A meta-analysis of individual patient data. Ann Intern Med. 34: 370-379.

The CARDS Investigators (2004). Primary prevention of cardiovascular disease with atorvastatin in type 2 diabetes in the Collaborative Atorvastatin Diabetes Study (CARDS): multicentre randomised placebo-controlled trial. Lancet 2004; 364: 685696.

The seventh report of the Joint National Committee on Prevention, Detection, Evaluation and Treatment of High Blood Pressure (2003). JAMA 289:2560-2572. 
The Task Force on the Use of Antiplatelet Agents in Patients with Atherosclerotic Cardiovascular Disease of the European Society of Cardiology (2004). Expert consensus document on the use of antiplatelet agents. Eur Heart J 25:166-81.

Thorn LM, Forsblom C, Fagerudd J, Pettersson-Fernholm K, Kilpikari R, Groop PH; FinnDiane Study Group (2007). Clustering of risk factors in parents of patients with type 1 diabetes and nephropathy. Diabetes Care 2007 May; 30(5): 1162-7. Epub 2007 Mar 2.

Tokuno A, Hirano T, Hayashi T, Mori Y, Yamamoto T, Nagashima M, Shiraishi Y, Ito Y, Adachi M (2007). The effects of statin and fibrate on lowering small dense LDLcholesterol in hyperlipidemic patients with type 2 diabetes. J Atheroscler Thromb. 2007 Jun; 14(3): 128-32.

Tonelli M, Moyé L, Sacks FM, Kiberd B, Curhan G; Cholesterol and Recurrent Events (CARE) Trial Investigators (2003). Pravastatin for secondary prevention of cardiovascular events in persons with mild chronic renal insufficiency. Ann Intern Med. 2003 Jan 21; 138(2): 98-104.

Veglio M, Sivieri R, Chinaglia A, Scaglione L, Cavallo-Perin P (2000). QT interval prolongation and mortality in type 1 diabetic patients: a 5-year cohort prospective study. Diabetes Care 23:1381-1383.

Weiner DE, Tighiouart H, Stark PC, Amin MG, MacLeod B, Griffith JL, Salem DN, Levey AS, Sarnak MJ (2004). Kidney disease as a risk factor for recurrent cardiovascular disease and mortality. Am J Kidney Dis 44(2): 198-206.

Weinrauch LA, Berger AJ, Aronson D, Gleason RE, Lee AT, D'Elia JA (2006). Regression of left ventricular hypertrophy in diabetic nephropathy: loss of parasympathetic function predicts response to treatment. J Clin Hypertens (Greenwich). 2006 May; 8(5): 330-5.

Whitsel EA, Boyko EJ, Siscovick DS (2000). Reassessing the role of QTc in the diagnosis of autonomic failure among patients with diabetes: a meta-analysis. Diabetes Care 23: 241-247.

Yilmaz MI, Saglam M, Qureshi AR, Carrero JJ, Caglar K, Eyileten T, Sonmez A, Cakir E, Oguz Y, Vural A, Yenicesu M, Stenvinkel P, Lindholm B, Axelsson J (2008). Endothelial dysfunction in type-2 diabetics with early diabetic nephropathy is associated with low circulating adiponectin. Nephrol Dial Transplant. 2008 May; 23(5):1621-7. Epub 2008 Jan 5.

Yokoyama H, Aoki T, Imahori M, Kuramitsu M (2004). Subclinical atherosclerosis is increased in type 2 diabetic patients with microalbuminuria evaluated by intimamedia thickness and pulse wave velocity. Kidney Int. 2004 Jul; 66(1): 448-54.

Yoshimura T, Suzuki E, Ito I, Sakaguchi M, Uzu T, Nishio Y, Maegawa H, Morikawa S, Inubushi T, Hisatomi A, Fujimoto K, Takeda J, Kashiwagi A (2008). Impaired peripheral circulation in lower-leg arteries caused by higher arterial stiffness and greater vascular resistance associates with nephropathy in type 2 diabetic patients with normal ankle-brachial indices. Diabetes Res Clin Pract. 2008 Jun; 80(3): 416-23. Epub 2008 Mar 11.

Zander E, Heinke P, Reindel J, Kohnert KD, Kairies U, Braun J, Eckel L, Kerner W (2002). Peripheral arterial disease in diabetes mellitus type 1 and type 2: are there different risk factors? Vasa. 2002 Nov; 31(4): 249-54. 
Zoccali C, Benedetto FA, Maas R, Mallamaci F, Tripepi G, Malatino LS, Böger R; CREED Investigators (2002). Asymmetric dimethylarginine, C-reactive protein, and carotid intima-media thickness in end-stage renal disease. J Am Soc Nephrol 13: 490-496. 


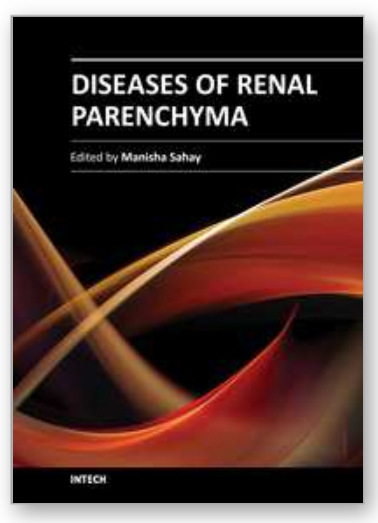

\author{
Diseases of Renal Parenchyma \\ Edited by Prof. Manisha Sahay
}

ISBN 978-953-51-0245-8

Hard cover, 304 pages

Publisher InTech

Published online 16, March, 2012

Published in print edition March, 2012

Clinical nephrology is an evolving speciality in which the amount of information is growing daily. This book gives quick access to some important clinical conditions encountered in nephrology including the diseases of glomeruli, tubules and interstitium. It presents the latest information on pathophysiology, diagnosis and management of important diseases of renal parenchyma. The information is presented in a very user friendly and accessible manner while the treatment algorithms enable the reader to quickly access expert advice on arriving at the most appropriate treatment regimen. The book discusses the renal involvement in various systemic diseases including diabetes and autoimmune diseases. Diabetic nephropathy is fast becoming the commonest cause of end stage renal disease all over the globe and is discussed in this book. The editors believe that this book will be a valuable addition to the reader's library.

\title{
How to reference
}

In order to correctly reference this scholarly work, feel free to copy and paste the following:

Caroline Jane Magri and Stephen Fava (2012). Diabetic Nephropathy: A Cardiovascular Risk Factor, Diseases of Renal Parenchyma, Prof. Manisha Sahay (Ed.), ISBN: 978-953-51-0245-8, InTech, Available from: http://www.intechopen.com/books/diseases-of-renal-parenchyma/diabetic-nephropathy-a-cardiovascular-riskfactor

\section{INTECH}

open science | open minds

\author{
InTech Europe \\ University Campus STeP Ri \\ Slavka Krautzeka 83/A \\ 51000 Rijeka, Croatia \\ Phone: +385 (51) 770447 \\ Fax: +385 (51) 686166 \\ www.intechopen.com
}

\author{
InTech China \\ Unit 405, Office Block, Hotel Equatorial Shanghai \\ No.65, Yan An Road (West), Shanghai, 200040, China \\ 中国上海市延安西路65号上海国际贵都大饭店办公楼 405 单元 \\ Phone: +86-21-62489820 \\ Fax: +86-21-62489821
}


(C) 2012 The Author(s). Licensee IntechOpen. This is an open access article distributed under the terms of the Creative Commons Attribution 3.0 License, which permits unrestricted use, distribution, and reproduction in any medium, provided the original work is properly cited. 